\title{
Performance of Ultrasound Techniques and the Potential of Artificial Intelligence in the Evaluation of Hepatocellular Carcinoma and Non-Alcoholic Fatty Liver Disease
}

\author{
Monica Lupsor-Platon ${ }^{1, *,+}\left(\mathbb{D}\right.$, Teodora Serban ${ }^{2,+} \oplus$, Alexandra Iulia Silion ${ }^{2, \ddagger}$, George Razvan Tirpe ${ }^{3, \ddagger}$, \\ Alexandru Tirpe ${ }^{4, \ddagger(1)}$ and Mira Florea ${ }^{5}$ \\ 1 Medical Imaging Department, Regional Institute of Gastroenterology and Hepatology, \\ Iuliu Hatieganu University of Medicine and Pharmacy, 400162 Cluj-Napoca, Romania \\ 2 Medical Imaging Department, Iuliu Hatieganu University of Medicine and Pharmacy, \\ 400162 Cluj-Napoca, Romania; teodora.serban@elearn.umfcluj.ro (T.S.); \\ alexandra.iuli.silion@elearn.umfcluj.ro (A.I.S.) \\ 3 County Emergency Hospital Cluj-Napoca, 3-5 Clinicilor Street, 400000 Cluj-Napoca, Romania; \\ razvantirpe@gmail.com \\ 4 Research Center for Functional Genomics, Biomedicine and Translational Medicine, \\ Iuliu Hatieganu University of Medicine and Pharmacy, 23 Marinescu Street, \\ 400337 Cluj-Napoca, Romania; altirpe@gmail.com \\ 5 Community Medicine Department, Iuliu Hatieganu University of Medicine and Pharmacy, \\ 400001 Cluj-Napoca, Romania; miraflorea@umfcluj.ro \\ check for \\ updates \\ Citation: Lupsor-Platon, M.; Serban, \\ * Correspondence: monica.lupsor@umfcluj.ro \\ + Monica Lupsor-Platon and Teodora Serban share the first coauthorship. \\ $\ddagger$ These authors have equal contribution to the work.
} T.; Silion, A.I.; Tirpe, G.R.; Tirpe, A.;

Florea, M. Performance of Ultrasound Techniques and the Potential of

Artificial Intelligence in the

Evaluation of Hepatocellular Carcinoma and Non-Alcoholic Fatty Liver Disease. Cancers 2021, 13, 790. https://doi.org/10.3390/

cancers13040790

Academic Editors: Helen L. Reeves and Luca Miele

Received: 15 November 2020

Accepted: 9 February 2021

Published: 14 February 2021

Publisher's Note: MDPI stays neutral with regard to jurisdictional claims in published maps and institutional affiliations.

Copyright: (c) 2021 by the authors. Licensee MDPI, Basel, Switzerland This article is an open access article distributed under the terms and conditions of the Creative Commons Attribution (CC BY) license (https:// creativecommons.org/licenses/by/ $4.0 /)$.
Simple Summary: The increasing prevalence of non-alcoholic fatty liver disease (NAFLD) represents a challenge for the current medical systems. If NAFLD is left undetected and untreated, it can progress towards fibrosis, cirrhosis, and hepatocellular carcinoma (HCC). To date, ultrasonography (US) is the first-line examination indicated to NAFLD patients that also screens for other focal liver lesions (FLLs). The downside of conventional B-mode US is that it cannot accurately quantify steatosis and fibrosis and cannot further characterize FLL certainly-is it cancer or is it not? Ultrasound contrast agents (UCAs) allowed physicians to further evaluate the FLL for the diagnosis of HCC. This review discusses the performance of US techniques in NAFLD and NAFLD-related HCC diagnosis, as well as of artificial intelligence (AI)-based methods, specifically the usefulness and assistance of deep learning algorithms for improving liver US image processing.

Abstract: Global statistics show an increasing percentage of patients that develop non-alcoholic fatty liver disease (NAFLD) and NAFLD-related hepatocellular carcinoma (HCC), even in the absence of cirrhosis. In the present review, we analyzed the diagnostic performance of ultrasonography (US) in the non-invasive evaluation of NAFLD and NAFLD-related HCC, as well as possibilities of optimizing US diagnosis with the help of artificial intelligence (AI) assistance. To date, US is the first-line examination recommended in the screening of patients with clinical suspicion of NAFLD, as it is readily available and leads to a better disease-specific surveillance. However, the conventional US presents limitations that significantly hamper its applicability in quantifying NAFLD and accurately characterizing a given focal liver lesion (FLL). Ultrasound contrast agents (UCAs) are an essential add-on to the conventional B-mode US and to the Doppler US that further empower this method, allowing the evaluation of the enhancement properties and the vascular architecture of FLLs, in comparison to the background parenchyma. The current paper also explores the new universe of $\mathrm{AI}$ and the various implications of deep learning algorithms in the evaluation of NAFLD and NAFLD-related HCC through US methods, concluding that it could potentially be a game changer for patient care. 
Keywords: hepatocellular carcinoma; non-alcoholic fatty liver disease; ultrasonography; contrast enhanced ultrasound; artificial intelligence; steatosis; focal liver lesion

\section{Introduction}

Hepatocellular carcinoma (HCC), the fourth leading cause of cancer mortality worldwide and the fifth and ninth most commonly diagnosed cancer in men and women, respectively, has changed its landscape. The incidence of non-viral HCC is increasing, since obesity, metabolic syndrome (MetS), and type 2 diabetes mellitus are a true epidemic [1,2]. Non-alcoholic fatty liver disease (NAFLD), the hepatic manifestation of the MetS, has become one of the leading causes of morbidity and mortality globally, affecting approximately $25 \%$ of the world's population [3,4]. NAFLD diagnosis requires identifying steatosis by imaging methods or histology, as well as the exclusion of significant alcohol consumption or other competing etiologies for fat accumulation [5-8]. The burden of NAFLD is especially important since it can progress towards fibrosis, cirrhosis, and NAFLD-related HCC [4]. Moreover, this pathology is recognized not only as the most common etiology of chronic liver disease, but as a major cause of cirrhosis and HCC, and it is expected to become the leading recommendation for liver transplantation in this decade [9,10]. Mittal et al. [11] reported that NAFLD individuals are fivefold more likely to develop HCC without underlying cirrhosis, compared to patients suffering from other chronic liver diseases. Notably, most NAFLD patients included in this study suffered from obesity and diabetes, supporting the pathogenetic hypothesis. The carcinogenesis process behind the HCC development in NAFLD is not completely understood, but different metabolic comorbidities, such as obesity and insulin resistance, are being incriminated, along with the pro-inflammatory status and the genetic predisposition identified in some patients [12]. It is well known that the presence and severity of fibrosis are important prognostic factors in NAFLD. Using combinations of non-invasive methods, such as composite scoring systems and/or transient elastography, enabled risk stratification of patients by fibrosis stage [13,14].

At present, ultrasonography (US) is the first-line imaging modality used for HCC screening among cirrhotic patients. Having a sensitivity of $40-81 \%$ and specificity of $80-100 \%$ for surveillance purposes, US is useful in cirrhotic and noncirrhotic patients, including NAFLD that should also undergo routine surveillance $[15,16]$. However, this technology encounters several limitations in the NAFLD population, considering that the body mass index (BMI) among these subjects is usually increased [17]. In addition, current guidelines lack specific recommendations for primary HCC prevention and, moreover, do not include clear recommendations for a cost-effective surveillance of the non-cirrhotic NAFLD patients carrying a risk of HCC development $[14,18]$. Surveillance among these individuals remains controversial since mass screening using conventional US has low cost-effectiveness [19]. Evidence of improved non-invasive diagnosis is in growing progress, requiring updating and reflection of data in clinical practice. In this review, we provide an updated analysis of the performance of ultrasound techniques and the potential contribution of artificial intelligence-based methods in the US evaluation of NAFLD/NASH and NAFLD-related HCC.

\section{Conventional Ultrasonography}

\subsection{Evaluating NAFLD Using Conventional US}

Currently, conventional US is recommended as the first-line examination for patients with high clinical suspicion of NAFLD, given the large number of advantages: It is cost effective, broadly available, non-invasive, appropriate for re-examination, and highly convenient for patients $[5-7,20,21]$. Ultrasound is sensitive $(85 \%)$ and specific $(95 \%)$ for detecting moderate to severe steatosis ( $>33 \%$ steatotic hepatocytes), but its sensitivity deteriorates when $<30 \%$ of hepatocytes are affected [21,22]. Moreover, increased echogenicity, the main US finding in NAFLD patients, is present in fibrosis and early cirrhosis as well, reducing the reliability of US in coexisting liver disease etiologies [13]. 


\subsubsection{Ultrasound Diagnostic Criteria for Hepatic Steatosis}

Besides hepatomegaly, the fat droplets interact with the ultrasound and a greater number of echoes return to transducer, displaying the well-known bright, hyperechoic liver, compared to the right kidney. Furthermore, the hyperechoic appearance of the liver results in a poor visualization of portal veins, liver capsule, and the gallbladder wall. In addition, lipids attenuate the ultrasound, leading to posterior darkness effect and a decreased visualization of the structures within the parenchyma and of the diaphragm, as seen in Figure 1. Also, altered liver hemodynamics detected with Doppler US can be seen, with one noteworthy example being the abnormal waveforms of the hepatic veins $[20,21,23-25]$.

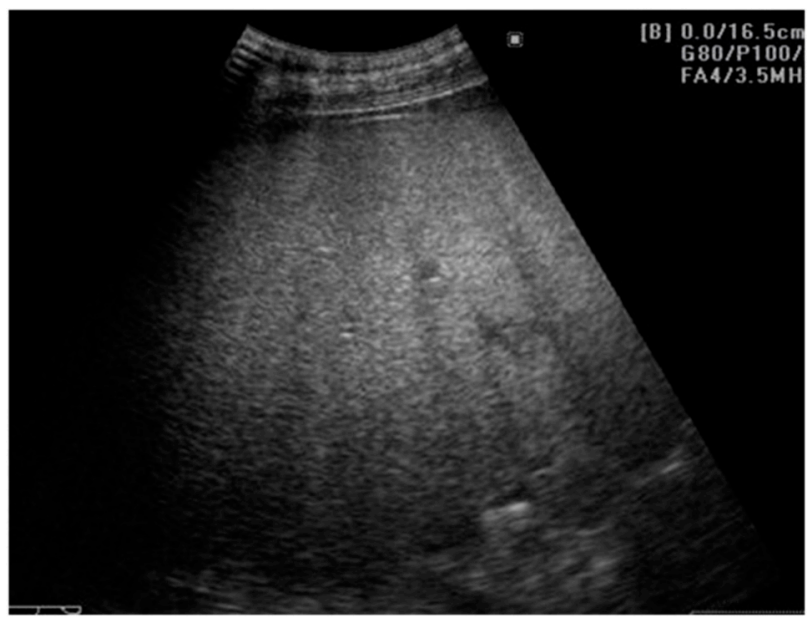

Figure 1. Hepatic steatosis. The 2D-US examination is showing an enlarged liver, with increased echogenicity and posterior beam attenuation, with a slightly inhomogeneous structure of fine granularity, without any FLLs. Even if this aspect is highly suggestive of hepatic steatosis, conventional US is unable to properly quantify the fatty amount of the liver. Also, 2D-US cannot specify whether fibrosis is present or not. Usually, steatosis and fibrosis coexist and therefore "steato-fibrosis" is the preferred term in this situation.

\subsubsection{Quantitative Assessment of Hepatic Steatosis}

The hyperechoic image is a qualitative feature and is dependent on the subjective interpretation of the examiner, leading to variability in results and low reproducibility [26]. A grading system of steatosis has been proposed in attempt to reduce the observer bias, using the hepatic, periportal, and diaphragmatic echogenicity, as exemplified in Table 1. However, all the criteria used to grade steatosis remain subjective.

Table 1. Criteria used in the B-mode US grading of steatosis [5,27].

\begin{tabular}{|c|c|}
\hline Grade & Ultrasonographic Features \\
\hline I: mild steatosis & $\begin{array}{c}\text { Liver echogenicity slightly increased and normal visualization of portal vein wall and the } \\
\text { diaphragmatic outline. }\end{array}$ \\
\hline II: moderate steatosis & $\begin{array}{l}\text { Liver echogenicity moderately increased with slightly impaired visualization of portal vein } \\
\text { wall and diaphragmatic outline. }\end{array}$ \\
\hline III: severe steatosis & $\begin{array}{l}\text { Liver echogenicity markedly increased with poor or no visualization of portal vein wall, } \\
\text { diaphragmatic outline, and posterior portion of the right hepatic lobe. }\end{array}$ \\
\hline
\end{tabular}

\subsubsection{US Performance for Steatosis Detection}

Conventional US is an accurate and highly reliable diagnostic tool for steatosis assessment. Wang et al. [28] found that the agreement rate of US as compared to histology is $61.4 \%$ in assessing the steatosis severity and $74.3 \%$ in diagnosing steatosis. A meta-analysis 
by Hernaez et al. [22] estimated that the US sensitivity to detect moderate and severe steatosis confirmed by histology is $84.8 \%$ and the specificity is $93.6 \%$. However, when mild steatosis is taken into consideration (fat content less than $20 \%$ ), the traditional US has low sensitivity and therefore a high false negative rate of 55\% [29]. The Dasarathy [29] prospective study observed that a combination of abnormal sonographic features increases the overall sensitivity and specificity. Another noteworthy remark was the fact that the sensitivity and specificity of hepatic vein blurring was higher than the one of the portal vein blurring, and there was a high concordance between hepatic vein blurring and the increased echogenicity. Therefore, the combination of portal vein blurring and liver brightness was a better sonographic predictor for hepatic steatosis [30].

Recently, a series of quantitative and semi-quantitative parameters have been implemented on US methods in order to overcome the limitation of low sensitivity in mild steatosis diagnosis. Some of these parameters exhibit a better performance than conventional US alone and have a better reproducibility and reliability [26,31-33]. Such parameters include attenuation (AC) and backscatter coefficients (BSC), the hepato-renal index (HRI) and ultrasound envelope statistic parametric imaging (known as speckle statistics). Hepatic steatosis correlates positively with these parameters. However, further studies are warranted to validate their potential widespread clinical use [31,34].

In addition, the controlled attenuation parameter (CAP) measured by the vibration controlled transient elastography (VCTE), a widely available device, has a powerful contribution in steatosis evaluation. The potential of US elastography is a subject of high interest in the non-invasive evaluation of NAFLD and NAFLD-related HCC, as previously exemplified in a recent paper from our group [14].

\subsubsection{Ultrasonographic Steatosis Patterns}

In the fatty liver, there are a number of different steatosis patterns that might be observed: diffuse, multinodular, focal geographic, focal nodular, intralesional, perilesional, subcapsular, periportal, perivenular steatosis, and hypersteatosis. Frequently, focal fatty infiltration occurs geographically, but pseudo-tumoral aspects are also possible [35]. Another mass like appearance can be given by areas of normal echogenicity as compared with the background hyperechoic parenchyma, termed "focal fatty sparing" (FFS). FFS are commonly found in segments IV and V, near the left portal vein or adjacent to the falciform ligament and the gallbladder fossa [36]. Due to their nodular appearance, FFS can lead to confusion with other focal liver lesions (FLLs) that have pathological implications.

\subsubsection{Limitations of Ultrasonography in Steatosis Diagnosis}

As previously mentioned, fibrosis is a key histologic feature that needs to be considered in NAFLD patients and especially in NASH subjects. Fibrosis is an important confounder for steatosis evaluation using US, as they both appear hyperechoic [37]. A study of 118 biopsy-proven NAFLD subjects found that US sensitivity for detecting moderate to severe histological steatosis was $100 \%$ among individuals with mild fibrosis on histology [37]. However, it decreased significantly to $77.8 \%$ in those with advanced fibrosis. In fact, several studies found no correlation between the US characteristics and the grade of inflammation, ballooning, and fibrosis identified on histology, making it challenging to distinguish between simple steatosis and progressive NASH [38,39]. Several studies proved that US was unable to discriminate between simple steatosis and NASH $[29,40]$.

Another limitation of US is the low sensitivity in patients with morbid obesity $\left(B M I>40 \mathrm{~kg} / \mathrm{m}^{2}\right)$ [41]. The subcutaneous fat reduces the ability of conventional US to evaluate liver echogenicity, especially among patients with high risk for NAFLD development [42]. In addition, as above mentioned, the method is unable to establish with certainty the degree of fatty infiltration. 


\subsection{NAFLD-Related HCC: Could Conventional and Doppler US Differentiate between Focal Liver Lesions (FLLs)?}

According to multiple guidelines, B-mode US is the primary imaging technique used for HCC screening in high-risk patients $[19,43]$. Although B-mode US cannot make a final diagnosis, the main goal is to detect any focal area differing from the background parenchyma. The method represents a milestone in selecting further management, being suggestive when a tumor displays signs of malignancy. Therefore, any suspicion of malignancy should be considered a positive result of the ultrasound exam, and further evaluation of the lesion will need to establish a specific diagnosis [44].

The US Liver Imaging Reporting and Data System (LI-RADS) score was established by the American College of Radiology (ACR) as an algorithm for the evaluation and management of FLLs in order to improve high-risk patient care [45]. According to the LI-RADS algorithm, the size threshold determines the further path to diagnosis. Lesions measuring less than $1 \mathrm{~cm}$ are difficult to assess with certainty, regardless of the imaging method. Nevertheless, they are usually benign and require follow-up at 3-4 months. If the tumor remains unchanged after 2 years of surveillance, malignancy is excluded [19,43,46]. For larger lesions, the US findings are inconsistent and an in-depth characterization is mandatory. Malignancy suspicion is raised by large focal lesions with heterogeneous echostructure and signs of parenchymal distortion-defined as ill-defined area of heterogeneity, refractive edge shadowing, and distortion of the normal internal hepatic architecture [47]. HCC of any size shows variable echogenicity, but as it develops, the tumor might undergo fatty metamorphosis, leading to a hyperechoic structure and a higher risk of being confused with a hemangioma [48]. Another important finding is a new thrombus identified in the liver venous system, more frequently within the portal veins, which can represent a bland thrombus or tumor and strongly indicates a diagnosis of HCC [45,49].

In addition, US Doppler assessment of blood flow and vascularization is useful, but not definitive (Figure 2) [48,50]. Central or peritumoral hypervascularity, basket pattern (vascular network at the periphery of tumor penetrating to the center) and the presence of pulsatile afferent flow signal with constant efferent flow are typical findings suggestive of HCC $[50,51]$. Moreover, spectral Doppler analysis offers parameters such as maximum flow velocity (Vmax) and pulsatility index (PI), which are useful in the differential diagnosis of several hepatic tumors. Notably, a very high value of the PI is suggestive for HCC, increasing the diagnostic efficacy of ultrasonic methods [47,52].

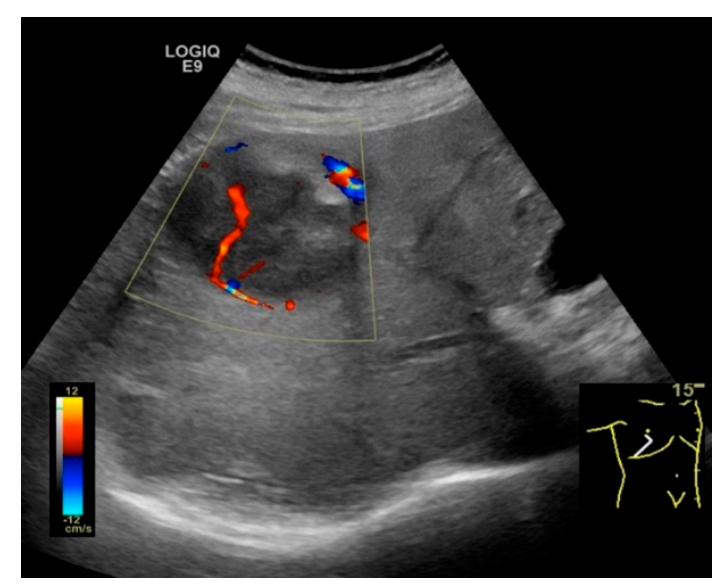

Figure 2. Hepatic steatosis. Focal liver lesion. 2D-US scan shows an enlarged liver with increased echogenicity and posterior beam attenuation. In addition, a focal parenchymal structure is observed in the right lobe. It is characterized as having decreased, heterogeneous echogenicity and internal vessels seen at Doppler examination. The diagnosis of the focal lesion remains uncertain and CEUS examination is necessary. 
In NAFLD subjects, a notable confounder is represented by focal fatty sparing areas. However, lesions with typical location and shapes, as previously mentioned, and without mass effect, are suggestive ultrasonographic features for FFS [53]. Moreover, one study implied that FFS usually do not develop on previously homogeneous NAFLD, implying that a new ultrasonographic observation should be compared to former US examinations [54]. US Doppler comes as an adjuvant tool for conventional US. Usually, FFS are not hypervascular and do not distort the normal hepatic vessels. Nevertheless, the final diagnosis requires further imaging modalities, including contrast enhanced US (CEUS), computed tomography (CT), magnetic resonance imaging (MRI), or even US-guided biopsy [55].

Of note is a 2018 meta-analysis conducted by Tzartzeva et al. [56] that found an all stage pooled sensitivity for HCC detection of $84 \%$ with US, approximately equal to the CT/MRI sensitivities. In the same study, sensitivity for early-stage HCC was only $47 \%$ with US and $63 \%$ when combined with alpha-fetoprotein level (AFP), proving the limited use of US for small tumor detection. In addition, US findings are not specific, as appearances of FLLs overlap [48,57]. US allows accurate diagnosis for few FLLs, of which hemangioma, simple cyst, and calcifications are the most common [49]. In the same manner, US Doppler is limited in the diagnosis of focal nodular hyperplasia (FNH), in which the central artery traversing the central scar and its radial distribution are evocative in $80 \%$ of cases [53]. Concluding, most FLLs require a definitive characterization with a diagnostic multiphase contrast-enhanced examination (CEUS, CT or MRI).

\section{Contrast-Enhanced Ultrasonography (CEUS): An Add-on to the Diagnostic Power of Ultrasonography in NAFLD-Related HCC}

\subsection{General and Technical Considerations}

Contrast-enhanced ultrasonography (CEUS) is a particular US technique that overcame several drawbacks of both the conventional B-mode and Doppler ultrasound techniques by adding the intravenous administration of microbubble contrast agents [58,59]. When analyzing the liver, CEUS provides real-time recording and interpretation of the ultrasound contrast agent (UCA) flow through the parenchyma. Dynamic contrast-enhanced ultrasound (DCE-US) has made quantitative assessment possible and readily available by analyzing the time intensity curve (TIC) and facilitating measurement of the blood flow parameters [60].

Currently, there are four Food and Drug Administration (FDA)-approved UCAs available worldwide: SonoVue/Lumason (Bracco Suisse SA, Geneva, Switzerland), Definity/Luminity (Lantheus Medical Imaging, Inc., North Billerica, MA, USA), Optison, and Sonazoid (GE Healthcare AS, Oslo, Norway) [61]. These UCAs consist of biodegradable gas microbubbles, equal or smaller in size than red blood cells, stabilized in a phospholipid or albumin shell $[58,59]$. Because of their physical size, all UCAs act as blood pool agents, allowing the representation of both small and large vessels [62]. While SonoVue, Definity and Optison are purely intravascular agents, Sonazoid is phagocytosed by the hepatic reticuloendothelial cells (Kupffer cells). This leads to increased clearance from the vascular distribution volume and significant persistence in the liver, termed the post-vascular phase (also known as the Kupffer cell phase). Regardless of whether microbubbles are within the reticuloendothelial system or utterly within the blood pool, they can be easily destroyed by the ultrasound energy emitted by the examiner, providing real-time visualization of different vascular phases [60]. Given the dual blood supply of the liver, from the hepatic artery and the portal vein $(25-30 \%$ and $70-75 \%$ of the total blood supply respectively), three different vascular phases have been defined: the arterial (AP), portal venous (PVP), and the late (LP) phase [61].

Moreover, UCAs enable the characterization of the vascular architecture through the phase-specific contrast enhancement in comparison to the background liver parenchyma. These characteristics are highly suggestive diagnostic features for various FLLs [60,61]. However, it is mandatory to perform a thorough B-mode and color Doppler US evaluation of the liver beforehand, considering that cysts and calcifications can be easily misinterpreted due to complete absence of enhancement. In addition, the assessment of 
the underlying parenchyma is paramount in order to ascertain whether cirrhosis is present or not, which can be a game changer [61].

\section{Indications, Advantages and Limitations of CEUS Compared to Conventional US}

Currently, clinical practice guidelines recommend abdominal US surveillance for malignancy every 6 months among cirrhotic patients $[19,43]$. However, the detection of small HCC nodules is difficult in subjects with liver cirrhosis, since they usually present a coarse parenchyma [63]. In addition, a high percentage of NAFLD-related HCC cases arise on non-cirrhotic liver [64]. As previously mentioned, steatosis and obesity independently impair US sensitivity in NAFLD patients [17]. CEUS improves the accuracy of B-mode US, by adding a new dimension to the equation-it evaluates the enhancement properties and vascular architecture of FLLs as compared to the background parenchyma [59]. In an experimental NASH rat model, Carvalho et al. [65] reported increased sensitivity and specificity (71\% and $96 \%$, respectively) after contrast administration, compared to Doppler US (29\% and $71 \%$, respectively). For integrative purposes, we decided to summarize the indications, advantages, and limitations of the conventional US compared to CEUS in Table 2.

Table 2. Indications, advantages, and limitations of CEUS as compared to B-mode and Doppler US.

\begin{tabular}{|c|c|c|}
\hline & Conventional B-Mode and Doppler Ultrasound & Contrast Enhanced Ultrasound (CEUS) \\
\hline Indications & $\begin{array}{l}\text { HCC surveillance for high risk patients }[19,43] \\
\text { Guides biopsy or treatment }[66]\end{array}$ & $\begin{array}{c}\text { Evaluates nodules } \geq 10 \mathrm{~mm} \text { observed at US } \\
\text { surveillance [59] } \\
\text { Guides biopsy or treatment for observations that are } \\
\text { undetectable or inconspicuous on US }[59,61] \\
\text { Selects the most relevant lesion/lesion component for } \\
\text { biopsy }[59,61] \\
\text { Evaluates lesions with inconclusive histology [59] } \\
\text { Better characterization of arterial phase enhancement in } \\
\text { inconclusive CT/MRI [59] } \\
\text { Differentiates between benign and malignant portal vein } \\
\text { thrombosis [59,61] } \\
\text { First line contrast imaging modality in patients with renal } \\
\text { insufficiency [61] }\end{array}$ \\
\hline Advantages & $\begin{array}{c}\text { Broadly available [20] } \\
\text { Free from ionizing radiation [21] } \\
\text { Cost-effective } \\
\text { Non-invasive } \\
\text { Typical HCC features of Doppler findings are } \\
\text { available [50] } \\
\text { The wide variety of Doppler methods } \\
\text { (color/spectral/power Doppler) for better } \\
\text { assessment of FLLs }[47,67]\end{array}$ & $\begin{array}{c}\text { UCAs are safe in adult and pediatric individuals [61] } \\
\text { The possibility of re-administration of UCAs for better } \\
\text { assessment of suspicious observations [61] } \\
\text { Avoids unnecessary further imaging for benign lesions [59] } \\
\text { Absence of ionizing radiation [68] } \\
\text { Real-time and quantitative assessment [61] } \\
\text { Cost-effective [69,70] } \\
\text { Excludes pseudovascular lesions detected on CT or MRI } \\
\text { such as arterioportal shunts [71] }\end{array}$ \\
\hline Limitations & $\begin{array}{c}\text { Low sensitivity in patients with morbid } \\
\text { obesity [41] } \\
\text { Steatosis leads to acoustic beam attenuation [36,72] } \\
\text { Unable to differentiate between simple steatosis } \\
\text { and progressive NASH [38,39] } \\
\text { Unable to differentiate between steatosis and } \\
\text { fibrosis [37] } \\
\text { Inadequate to assess with certainty the degree of } \\
\text { fatty infiltration [30] } \\
\text { Focal fatty deposition or sparing areas can lead to } \\
\text { confusion with other FLLs [35] } \\
\text { Low sensitivity for early-stage HCC [56] } \\
\text { Overlap of FLL appearance on the US image [57] }\end{array}$ & $\begin{array}{c}\text { Unsuitable for HCC staging [60] } \\
\text { Subdiaphragmatic or deep lesions are difficult to reach and } \\
\text { characterize properly [59] } \\
\text { Limited penetration in obese patients [59] } \\
\text { Severe hepatic steatosis alters signal transmission through } \\
\text { the parenchyma [59] }\end{array}$ \\
\hline
\end{tabular}




\subsection{Assessment of Fatty Liver Progression Using CEUS}

Studies evaluating chronic liver diseases using CEUS are rather scarce. However, fat accumulation is the key factor that leads to vascular impairment and increased vascular resistance. Technologies such as CEUS can appraise hepatic microcirculation and quantify early changes in the parenchymal flow, before the onset of fibrosis [73,74]. There are several in vivo studies that evaluated fatty liver progression and HCC development using untargeted CEUS $[65,75,76]$. Of note is the Pandit study [75] that identified disease progression using vascular parameters, concluding that NASH liver parenchyma has the lowest blood flow. On the other hand, Tsujimoto et al. [76] evaluated Kupffer cells dynamic and phagocytic activity in a rat NASH model using Levovist and observed a reduced contrast effect in the liver. In humans, several studies using transit time parameters, such as the hepatic vein transit time (HVTT), evaluated fibrosis in different chronic liver diseases including NAFLD, chronic hepatitis B, and chronic hepatitis C. They observed earlier arrival time of contrast agents in the hepatic veins in severe fibrotic patients, compared to their healthy counterparts, and concluded that intrahepatic hemodynamic changes, such as shunts or liver arterialization, play an important role in these changes [77-80]. To summarize, Table 3 embodies an overview of different techniques for fatty liver assessment.

Table 3. Characteristic of NAFLD by different non-invasive methods.

\begin{tabular}{|c|c|}
\hline Technique & Features \\
\hline B-mode US & $\begin{array}{l}\text { Hepatomegaly } \\
\text { Bright, hyperechoic liver compared to the right kidney } \\
\text { Posterior beam attenuation }\end{array}$ \\
\hline Doppler US & $\begin{array}{c}\text { Abnormal waveforms of the hepatic veins (normal triphasic pattern disappears) [81] } \\
\text { Velocity of the portal flow (flow peak maximum velocity and mean flow velocity) and the portal vein } \\
\text { pulsatility index (VPI) are significantly lower in patients with fatty liver when compared to the controls; it also } \\
\text { corelates with the severity of the fatty liver [82] }\end{array}$ \\
\hline US elastography & $\begin{array}{l}\text { Fibrosis assessment by means of hepatic stiffness measurement } \\
\text { Steatosis evaluation by the instrumentality of the Controlled Attenuation Parameter (CAP) [14] }\end{array}$ \\
\hline CEUS & $\begin{array}{l}\text { Earlier arrival time of contrast agents in hepatic veins using the hepatic vein transit time (HVTT) } \\
\text { Reduced contrast effect in the Kupffer cell phase }\end{array}$ \\
\hline
\end{tabular}

\subsection{The Evaluation of FLLs, Including HCC, in NAFLD Patients Using CEUS}

Over the years, international guidelines sought to elucidate the role of CEUS for FLLs evaluation. At first, CEUS was considered an inappropriate diagnostic tool for HCC surveillance, and more expensive technologies, such as Contrast Enhanced CT (CeCT) or Contrast Enhanced MRI (CeMRI), were preferred [83,84]. However, in the past years, additional evidence has been published for all UCAs and proved otherwise [61]. The DEGUM multicenter trial [85-87], together with the multicenter study of Sporea et al. [88], showed that CEUS possesses powerful capacity in differentiating between malignant versus benign FLLs, as exemplified in Table 4. CEUS sensitivity ranges from $80-94 \%$ for all size focal lesions and $55-76 \%$ for those $\leq 20 \mathrm{~mm}$, and the specificity from $82-98 \%$ for all size liver nodules and $80-98 \%$ for those $\leq 20 \mathrm{~mm}$, providing similar performance to CT and MRI for characterizing FLLs $[86,88,89]$. Having $63-76 \%$ sensitivity and $87-98 \%$ specificity, CT enables full crosssectional evaluation of the liver and provides staging information. Gadolinium-enhanced MRI offers a better depiction of intrinsic tumor characteristics than CT with $67-82 \%$ sensitivity and $86-94 \%$ specificity. Moreover, Gadoxetate-enhanced MRI is very sensitive for early and small lesions $(\leq 20 \mathrm{~mm}$ ) with $90-93 \%$ sensitivity and $87-91 \%$ specificity, facilitating the differentiation of early HCCs from cirrhosis-associated benign nodules. Functional MRI techniques, including diffusion-weighted imaging, MRI with hepatobiliary contrast agents, perfusion imaging, and magnetic resonance elastography are promising in providing additional imaging features for tumor microvascular invasion and growth patterns, allowing preoperative 
prediction and prognosis [90]. Emerging as the most accurate and cost-effective imaging modality for FLLs characterization, CEUS is currently recommended as the first-line method for hepatic lesions evaluation, especially in patients with inconclusive CT or MRI findings, or among those with contraindications for these techniques [61]. In addition, recent analyses reported that Sonazoid CEUS surveillance might be a cost-effective method to increase expected survival time among at-risk subjects $[67,91]$. However, routine use of CEUS for HCC screening among patients at risk is currently not recommended and further research is needed to find ways to integrate such technologies into the healthcare surveillance strategies [61]. 
Table 4. CEUS capacity using different contrast agents (SonoVue, Sonazoid, Levovist) for differentiating between malignant versus benign FLLs.

\begin{tabular}{|c|c|c|c|c|c|c|c|c|c|c|c|c|}
\hline \multirow{3}{*}{ Study } & \multirow{3}{*}{ UCA Used } & \multirow{3}{*}{ AUROC } & \multicolumn{4}{|c|}{ Malignant Lesions } & \multicolumn{6}{|c|}{ Benign Lesions } \\
\hline & & & \multicolumn{2}{|c|}{ HCC } & \multicolumn{2}{|c|}{ Metastases } & \multicolumn{2}{|c|}{ Hemangioma } & \multicolumn{2}{|c|}{ FNH } & \multicolumn{2}{|c|}{$\begin{array}{l}\text { Hepatocellular } \\
\text { Adenoma }\end{array}$} \\
\hline & & & Se $(\%)$ & Sp (\%) & Se $(\%)$ & $\mathrm{Sp}(\%)$ & Se (\%) & $\mathrm{Sp}(\%)$ & Se $(\%)$ & $\mathrm{Sp}(\%)$ & Se $(\%)$ & Sp (\%) \\
\hline \multirow{2}{*}{ Auer et al. [92] } & \multirow{2}{*}{ SonoVue } & \multirow{2}{*}{0.951} & 100 & 100 & 90 & 100 & 99 & 100 & 100 & 100 & 66.6 & 100 \\
\hline & & & \multicolumn{2}{|c|}{$(n=7)$} & \multicolumn{2}{|c|}{$(n=31)$} & \multicolumn{2}{|c|}{$(n=74)$} & \multicolumn{2}{|c|}{$(n=19)$} & \multicolumn{2}{|c|}{$(n=3)$} \\
\hline Sawatzki et al. [93] ${ }^{1}$ & SonoVue & $\mathrm{N} / \mathrm{S}$ & \multicolumn{4}{|c|}{$\begin{array}{c}\mathrm{Se}=96-97.2^{\#} \\
(n=37)\end{array}$} & & & \multicolumn{2}{|c|}{$\begin{array}{c}\mathrm{Sp}=84.2-90.6^{\#} \\
(n=75)\end{array}$} & & \\
\hline \multirow[b]{2}{*}{ Zhang et al. [94] * } & SonoVue & \multirow{2}{*}{0.94} & 85 & 91 & \multirow{2}{*}{\multicolumn{2}{|c|}{$\mathrm{N} / \mathrm{S}$}} & & & \multirow{4}{*}{\multicolumn{2}{|c|}{$\mathrm{N} / \mathrm{S}$}} & & \\
\hline & $\begin{array}{l}\text { Sonazoid } \\
\text { Levovist }\end{array}$ & & \multicolumn{2}{|c|}{$(\mathrm{N} / \mathrm{S})$} & & & & & & & & \\
\hline \multirow{2}{*}{ Yue et al. [95] ${ }^{2}$} & \multirow{2}{*}{ SonoVue } & \multirow{2}{*}{0.70} & \multirow{2}{*}{\multicolumn{4}{|c|}{ 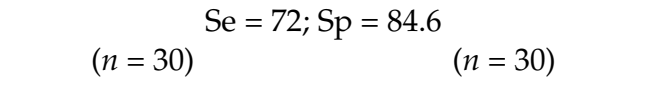 }} & & & & & & \\
\hline & & & & & & & & & & & & \\
\hline \multirow{2}{*}{ Deng et al. [96] * } & Sonazoid & \multirow{2}{*}{0.93} & 86 & 87 & \multirow{2}{*}{\multicolumn{2}{|c|}{$\mathrm{N} / \mathrm{S}$}} & & & & & & \\
\hline & Levovist & & $(n=$ & 104) & & & & & & & & \\
\hline Sporea et al. [88] & SonoV/10 & $N / S_{1}$ & 81.2 & 94.2 & 93.1 & 94.1 & 90.2 & 97.6 & 94.7 & 98.4 & & \\
\hline & SonoVue & $N / S$ & 88 & $\mathrm{~N} / \mathrm{S}$ & 91 & $\mathrm{~N} / \mathrm{S}$ & 86 & $\mathrm{~N} / \mathrm{S}$ & 88 & $\mathrm{~N} / \mathrm{S}$ & & \\
\hline 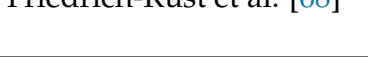 & Levovist & & & & & 75) & & 91) & & & & \\
\hline Xie et al. [97] * & $\begin{array}{l}\text { SonoVue } \\
\text { Levovist }\end{array}$ & 0.9555 & & & & & & & & & & \\
\hline Strobel et al. [86] & SonoVue & $\mathrm{N} / \mathrm{S}$ & & $\begin{array}{c}\mathrm{Se} \\
(n\end{array}$ & & & & & & $\begin{array}{l}67^{\#} \\
7)^{4}\end{array}$ & & \\
\hline & & & 86.1 & 96.6 & 93.6 & 82.4 & 62.5 & 97.3 & 57.1 & 99.3 & & \\
\hline Seitz et al. [85] & SonoVue & $\mathrm{N} / \mathrm{S}$ & $(n=$ & $0 * *)$ & $(n=$ & $\left.6^{* *}\right)$ & $(n=$ & $\left.9^{* *}\right)$ & $(n=$ & $\left.14^{* *}\right)$ & & \\
\hline
\end{tabular}

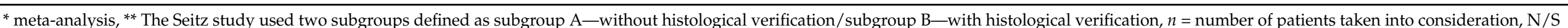

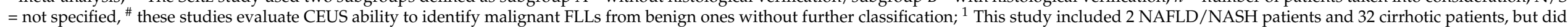
not use the CEUS LI-RADS algorithm; ${ }^{2}$ This study used parametric imaging CEUS, differentiating between HCC and metastatic liver cancer using quantitative parameters. 


\subsubsection{Diagnostic Features of Hepatocellular Carcinoma on CEUS}

The major features for HCC diagnosis on CEUS are arterial phase hyperenhancement followed by mild washout with late onset in the portal and/or late phase, as depicted in Figure $3[59,98]$. However, studies demonstrated that the enhancement patterns largely depend on the degree of arterial vascularization and the differentiation grade of the tumor $[99,100]$. In regards to the vascularization, studies reported arterial phase hyperenhancement in $90-97.8 \%$ of HCC lesions while hypoenhanced observations were mainly well differentiated HCCs $[87,98,100,101]$. In spite of that, Von Herbay et al. [102] reported 28\% non-hyperenhanced HCC nodules. These results might be explained by the inclusion of undifferentiated (G4) HCC nodules, considered by Yang et al. [98] as FLLs with decreased arterial supply. Regarding the diameter of the FLL, the Von Herbay study found a significantly higher incidence $(95 \%)$ of hypervascularization in larger $(>3 \mathrm{~cm})$, well differentiated (G1) HCC lesions, in comparison to smaller $(<3 \mathrm{~cm})$ G1 HCCs (43\%) [102].

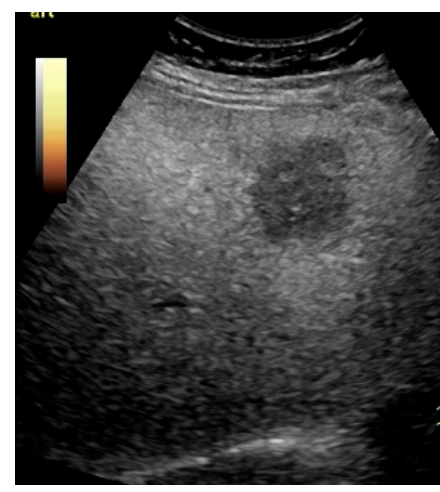

(a)

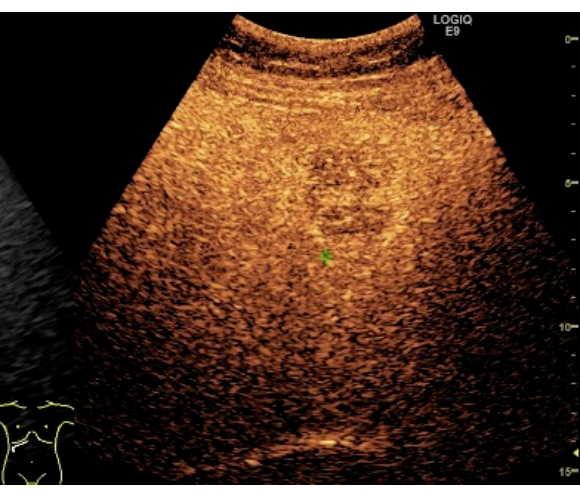

(b)

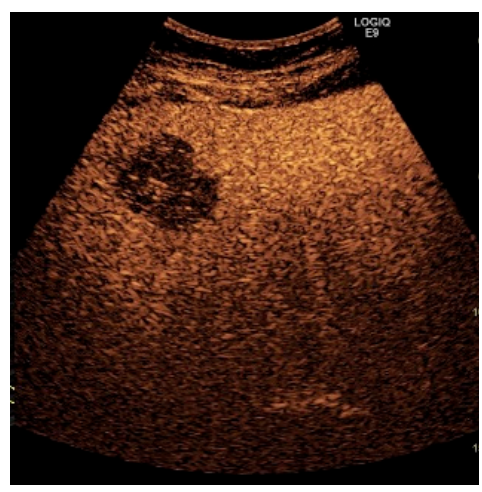

(c)

Figure 3. Hepatic steatosis. HCC. Conventional B-mode image (a), CEUS in the arterial phase (b), and CEUS in the late phase (c). The examination shows an enlarged liver with markedly increased echogenicity and a focal parenchymal lesion with decreased echogenicity (a). At CEUS technique, the lesion shows enhancement in the arterial phase (b), followed by washout in the late phase (c).

Mechanistically, the relationship between washout patterns and cellular differentiation is influenced by the amount of portal veins in the suspected nodule. In the multistep hepatocarcinogenesis, the supplying vessels undergo major changes, with normal arteries and portal veins decreasing, while the abnormal neoplastic arteries increase [103]. Therefore, HCC with poorer grades of differentiation tend to present moderate washout, whereas well differentiated HCCs are likely to be iso-enhancing in the LP $[99,100,104]$. Another key feature for HCC evaluation consists of proper assessment of washout chronology. As a real-time imaging technique, CEUS enables precise assessment of washout onset, a fundamental characteristic for the CEUS LI-RADS classification. HCC typically shows washout with late onset (>60 s), while non-hepatocellular lesions, including intrahepatic cholangiocarcinoma (ICC), present early washout onset (<60 s) [59].

The combined appraisal of the aforementioned diagnostic features makes it possible to evaluate the FLLs as malignant or benign in patients without underlying cirrhosis [87]. In those with liver cirrhosis and other risk factors for HCC development, CEUS can detect and characterize FLLs according to the LI-RADS classification. Released in 2016, CEUS LIRADS is a standardized algorithm that classifies observations from LR-1 (a definitely benign lesion) to LR5 (an undoubtedly HCC). The LR score spectrum is illustrated in Figure 4. This table includes only CEUS pure blood pool agents (SonoVue, Luminity) [59,105-108]. A novel system proposed by Schellhaas et al. [109] redefined the population at risk for HCC, including patients with NASH and chronic hepatitis C with advanced fibrosis together with other key differences from the official CEUS LI-RADS. Nonetheless, their proposal was considered misleading by the ACR and consequently denied [110]. 


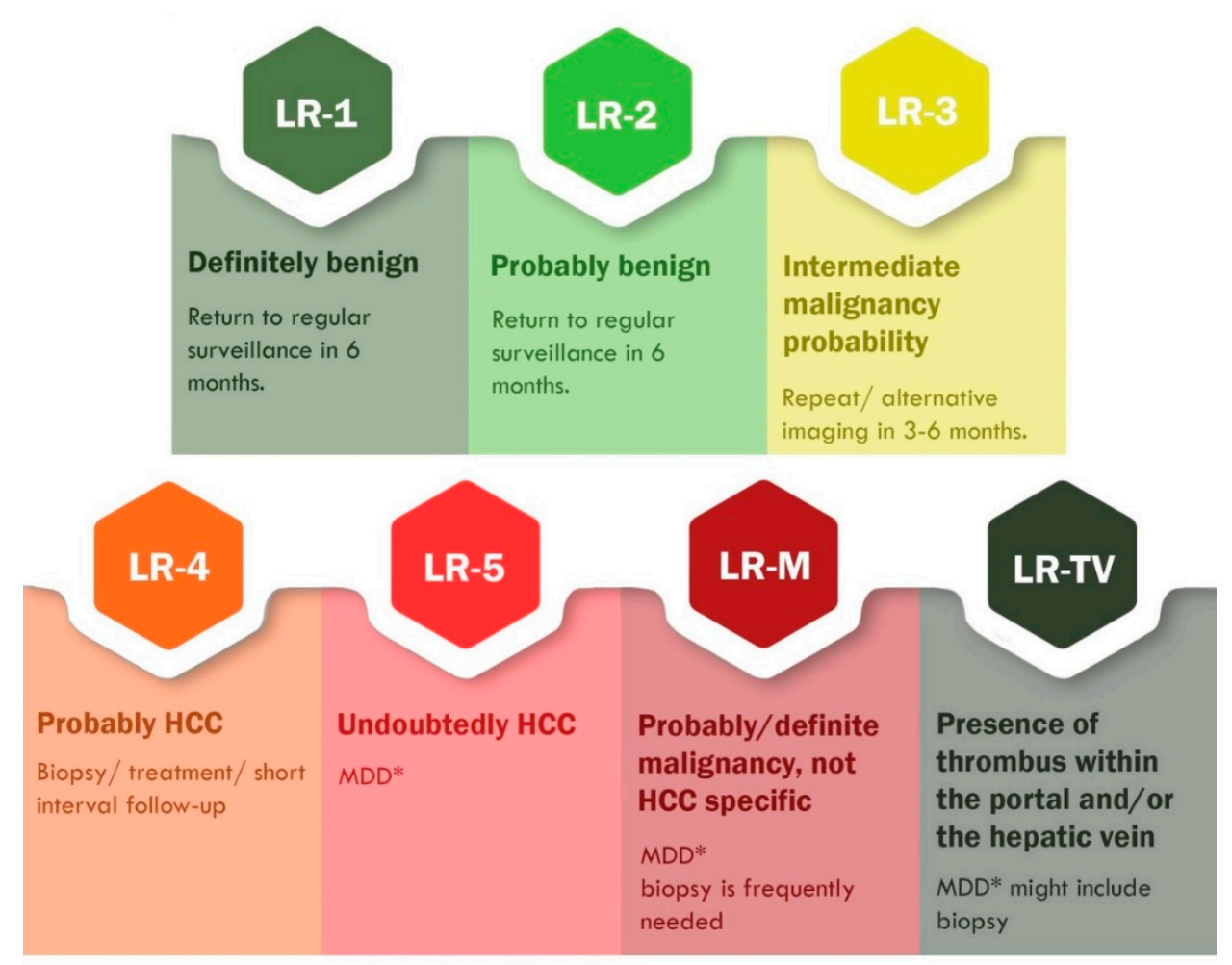

Figure 4. CEUS LI-RADS classification and management of FLLs according to the American College of Radiology [59,111]. This table includes only CEUS pure blood pool agents (SonoVue, Luminity). * MDD: multidisciplinary discussion; \#MDD should be considered, since a recent prospective study found that $60 \%$ of CEUS LR-3 observations were HCCs [112].

\subsubsection{HCC Particularities in NAFLD Patients}

FLLs are frequent findings in clinical practice in patients with chronic liver diseases, such as cirrhosis or steatosis. One important aspect of HCC among NAFLD subjects remains its arduous detection. This is mainly due to subcutaneous fatty accumulation in addition to hepatic steatosis, which may alter the US visualization of small or early stage HCC nodules. Therefore, screening among these individuals remains controversial due to low cost-effectiveness. However, the recent study by Harris et al. [113] emphasized that screening among obese and NAFLD patients is of great interest and that clinicians should consider alternative imaging methods if US is limited.

Another important aspect among NAFLD patients remains the wide variety of differential diagnosis. In particular, focal fatty changes, either by fat depositions or fatty sparing, may also occur, impairing the diagnostic accuracy of B-mode US examination. However, an iso-enhancing observation during all phases, without washout on CEUS, enables proper diagnosis, without the need for further imaging (Figure 5) [59,114]. Also, several studies aimed to elucidate whether underlying hepatic condition may alter lesions enhancement patterns. Yang et al. [98] reported no significant difference on the dynamic enhancement of HCC using CEUS in patients with or without cirrhosis.

\subsubsection{Sonazoid-Enhanced US-A Breakthrough in the CEUS Practice}

As mentioned beforehand, Sonazoid accumulates in the reticuloendothelial system. Moreover, Sonazoid-enhanced US facilitates FLLs characterization, histological grading and guided percutaneous ablation therapy $[115,116]$. It is well-known that macrophages play an important role in malignancies [117]; Kupffer cells are specialized macrophages localized within the lumen of the liver sinusoid; the absence of these Kupffer cells in poorly differentiated HCCs usually causes contrast defect, corresponding to hypo-enhancement in the post vascular phase [58]. Nonetheless, in the Arita study [118], half of the well differentiated HCCs did not show lacking enhancement in the Kupffer cell phase. Recently, 
a meta-analysis by Wu et al. [119] found that Sonazoid has the highest diagnostic accuracy among all UCAs. However, being available only in Japan, South Korea, and Norway so far, only four studies were included in the Wu meta-analysis. Therefore, further worldwide research is needed in order to integrate Kupffer cell agents in the CEUS LI-RADS algorithm for FLLs characterization, considering the large palette of advantages that this method could bring to the clinician [105].

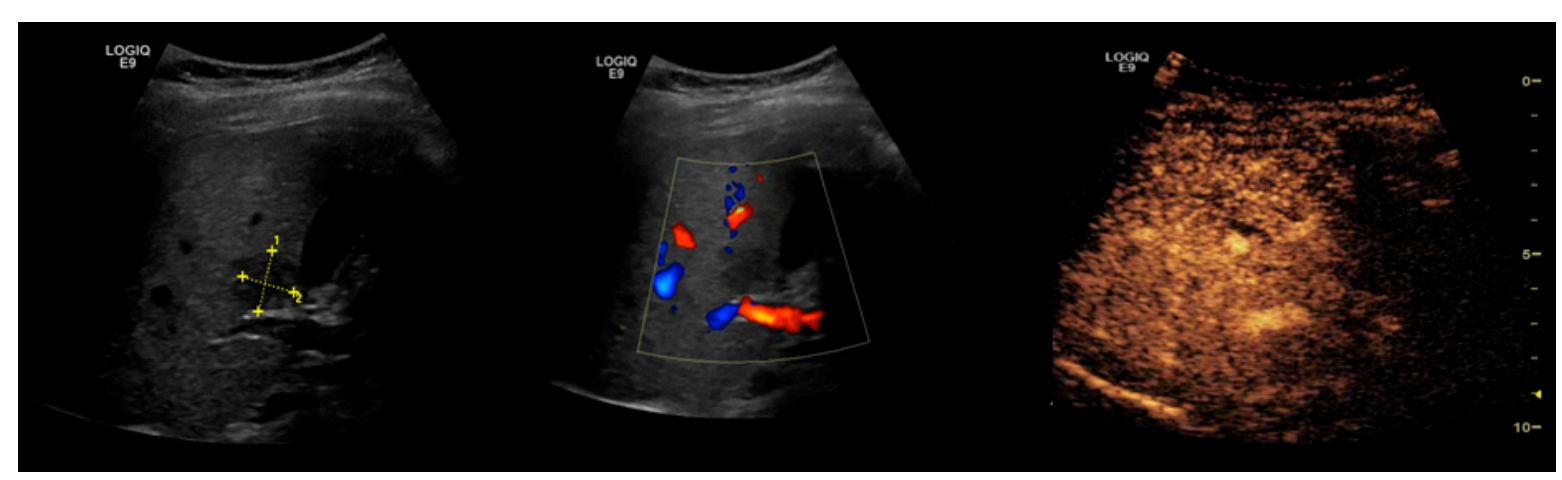

Figure 5. Focal sparing in the pericholecystic region. Hypoechoic image located around the gallbladder in a fatty liver. The Doppler examination cannot reveal any vessels within the lesion. On CEUS, the enhancement was homogeneous during the arterial, portal, and parenchymal phases, without any apparent focal lesions.

\section{Artificial Intelligence in the Ultrasonographic Evaluation of NAFLD and NAFLD-Related HCC: A Potential Pillar}

Ultrasound imaging is a widely used technique in today's clinical practice. It provides both qualitative and quantitative information in a non-invasive manner, which benefits the patient. The classic examination performed by the radiologist/radiographer is operatordependent, subjective, and cannot differentiate between steatosis and fibrosis; furthermore, conventional B-mode US is not able to establish the exact amount of fat accumulation in the hepatocytes. Artificial intelligence could revolutionize the evaluation of the images through a detailed and comprehensive analysis. Computerized image analysis can detect different textures from the ultrasound acquisitions, based on the physical and architectural alterations that affect the propagation of US waves. The use of computers in US image analysis started several years ago with the introduction of methods like grayscale analysis, ultrasound histogram, attenuation and/or texture information, and computer-assisted quantitative analysis of ultrasound beam echo amplitude [120-122]. Another method that can appraise steatosis severity is the computerized calculation of the hepatorenal ratio, with a sensibility of $91.3 \%$ and a specificity of $83 \%$ if the hepato-renal difference is $\geq 7 \mathrm{~dB}$ [30]. However, the efficacy of these rudimentary computerized methods remains questionable and the progress towards the applications of artificial intelligence is within our grasp.

In the past years, artificial intelligence (AI)-based methods, especially deep learning (DL) algorithms, gained extensive attention in the field of ultrasound imaging. In broad terms, we highlight two AI techniques with applications within the imaging field-machine learning (ML)-based algorithms with its more advanced class of DL. Convolutional neural networks (CNNs) are the most popular DL architecture used in medical imaging, although they require large amounts of training data $[123,124]$. AI-based algorithms that guide the examiner towards the best image acquiring position have been developed, so that, in the future, the examiner will not necessarily need to have previous US technique knowledge. In the near future, DL algorithms may provide accurate interpretation of various US images acquired by the examiner while returning a probable imaging diagnosis [125], assisting the physician in completing the clinical diagnosis and prioritizing urgent cases based on entities identified in the scans [126]. This section aims to discuss the current state of the AI research in the US evaluation of NAFLD and NAFLD-related HCC, focusing on the clinical applications of AI-based methods rather than the technology behind it. 
Radiomics emerged as a new method in improving the accuracy of the clinical decision making based on medical imaging reports. It refers to the high-throughput mining of data from medical imaging. In general terms, the workflow of radiomics begins with the first step referring to the acquisition of standardized images, followed by the segmentation of the entities present within the image (either automatically, or by the physician) in order to define the desired region of exploration. Next, quantitative features, such as intensity levels, texture pattern, shapes, and the spatial interrelation of different entities are retrieved from the selected region with a consequent analysis based on complex algorithms. The most prominent data are investigated in relationship with treatment and prognosis, the main goal being accurate risk stratification [127-129].

From a brief technical perspective, the goal of the machine learning (ML) techniques is to study the underlying US features and transform them into information for segmentation or classification [130]. Furthermore, ML methods can be supervised and unsupervised; in supervised ML algorithms, the classifier is trained on an existing database containing US images that are labeled with the required outputs. Contrarily, unsupervised learning algorithms identify similarities in the input data, with no labels provided [131].

DL methods are a subclass of machine learning algorithms in computer science [130]. In the learning phase of DL algorithms, the labeled US images are randomly divided into two separate groups - training and validation; images from within the training group are used to automatically identify features and a specific model learned. Next, the validation group is used in order to estimate the performance of the best learned model identified. The DL algorithm will then be able to apply the learned algorithm to analyze a new US image and to make predictions. [131]. CNNs are the most popular DL architecture used in medical imaging and are inspired from the biologic neural networks, containing multiple computational units entitled artificial neurons that analyze the input images [132].

An unsupervised neural network that is worth mentioning is represented by stacked autoencoders. Briefly, these algorithms learns the representation of the input data by attempting to reconstruct it [130].

\subsection{The Applications of AI in the Ultrasonographic Evaluation of NAFLD}

As mentioned beforehand, the gold standard for NAFLD diagnosis is biopsy, but its invasiveness severely limits the method to specialized healthcare units. Currently, US is an invaluable non-invasive technique in the first-line examination of patients with clinical suspicion of NAFLD. Although a number of studies have tried to standardize a grading system for the US evaluation of NAFLD, all criteria still remain subjective. Considering that the Hernaez meta-analysis found a $84.8 \%$ sensitivity and a $93.6 \%$ specificity for detection of moderate and severe steatosis, whilst mild steatosis had considerably lower sensitivity [22], we sought to determine whether AI could potentially improve the US detectability of NAFLD.

A study by Han et al. [133] sought to evaluate DL algorithms that use radiofrequency (RF) data for NAFLD evaluation, analyzing 204 participants with 140 NAFLD-affected patients. Reference was set with MRI-derived proton density fat fraction (PDFF). Two onedimensional CNN algorithms were developed - a binary classifier and a fat fraction estimator. Furthermore, the Han study divided participants into training group $(n=102)$ and test group $(n=102)$ by stratified randomization. The CNN algorithms were then developed through cross-validation, using the training group, and further evaluated in the test group. The Han study showed a high classification accuracy classifier (96\%) with an AUROC of 0.98. Moreover, the sensitivity in the RF without time gain compensation was 97\% [95\% CI: 90-100\%] and specificity 94\% [95\% CI: 79-99\%] [133].

Furthermore, in a study by Biswas et al. [134] that included 63 patients, the accuracy, sensitivity and specificity for detecting fatty liver disease and making the risk stratification based on deep learning ultrasound (US) was 100\%. The AUROC of deep learning method was 1.0 compared to extreme learning machine, which had an AUROC of 0.9222, sensitivity of $93.33 \%$ and specificity of $90.83 \%$; support vector machines (SVM) had an AUROC of 
0.8208 , average sensitivity of $64.21 \%$, and specificity of $93.56 \%$, highlighting the better performances of deep learning technology in this study. Another study by Byra et al. [135] proposed the use of a CNN model for liver steatosis assessment in B-mode ultrasound imaging. Their work included 55 severe obese patients, 38 of whom had fatty liver disease. The overall result was significantly better than conventional B-mode US, with an AUROC of 0.977 , accuracy of $96.3 \%$, sensitivity of $100 \%$ and specificity of $88.2 \%$, whereas the accuracy when using the hepatorenal index was $90.9 \%$ and the accuracy of gray-level co-occurrence algorithm was $85.4 \%$. The Cao study [136] recruited 240 patients from routine abdominal US examinations and compared the performance of envelope signal value, gray scale value, and deep learning in diagnosing NAFLD, as well as differentiating between mild, moderate, and severe steatosis. The DL index did not follow a Gaussian distribution, but presented obvious differences between the mild, moderate, and severe NAFLD groups. In the Cao study, in terms of diagnosing NAFLD, deep learning-based algorithm had the best performance, with the highest DL index and an AUROC of 0.933, compared to gray scale value (AUROC $=0.857$ ) and envelope signal (AUROC $=0.859$ ). Whilst all three methods showed poor diagnostic capability in terms of NAFLD scoring between mild and moderate NAFLD (AUROC < 0.7), DL index showed much better capability $($ AUROC $=0.958)$ in distinguishing between moderate and severe NAFLD [136]. As such, the existing data within the literature suggests that deep learning methods can be a viable addition to the current clinical practice in diagnosing NAFLD. However, further studies are required in order to standardize this approach.

\subsection{The Applications of AI in the Ultrasonographic Evaluation of NAFLD-Related HCC}

The clinical day-to-day life proved that there is a need to detect HCC in early stages, but the current limitations regarding imaging techniques hamper the early diagnosis of this malignancy. AI is constantly and steadily evolving and could become an important player in early detection and staging. For comprehensibility purposes, Table 5 presents a brief overview upon the latest studies involving the potential of AI in the US detection of HCC and NAFLD-related HCC.

Table 5. A brief overview upon a selection of recent studies that evaluate the potential of AI techniques in the detection of HCC and NAFLD-related HCC.

\begin{tabular}{|c|c|c|}
\hline Study & AI Technical Considerations & Accuracy of the AI Method \\
\hline Bharti et al. [137] & Deep learning & $\begin{array}{l}\text { Detection of } \\
\text { - } \quad \text { Normal liver }(n=24 \text { patients): } \mathrm{Se} / \mathrm{Sp}=96.3 \% / 99.2 \% \\
\text { - } \quad \text { CLD }(n=25 \text { patients): Se } / \mathrm{Sp}=95.5 \% / 98.0 \% \\
\text { - } \quad \text { Cirrhotic liver }(n=25 \text { patients): } \mathrm{Se} / \mathrm{Sp}=97.5 \% / 98.2 \% \\
\text { - } \quad \text { HCC on a cirrhotic liver }(n=20 \text { patients): Se } / \mathrm{Sp}=96.9 \% / 99.8 \%\end{array}$ \\
\hline Hassan et al. [138] & Deep learning & $\begin{array}{l}\text { Detection of HCCs, liver cysts and hemangiomas } \\
\text { - } \quad \text { Se/Sp for the classification performance: } 98.0 \% / 95.7 \% \\
\text { - } \quad \text { Overall accuracy: } 97.2 \%\end{array}$ \\
\hline Sato et al. [139] & Machine learning & $\begin{array}{l}\text { Prediction of HCC }(n=539 \text { patients with } \mathrm{HCC}, n=1043 \text { patients } \\
\text { without HCC) } \\
\text { - } \mathrm{Se} / \mathrm{Sp}=93.27 \% / 75.93 \% \\
\text { - } \quad \mathrm{AUC}=0.940\end{array}$ \\
\hline Schmauch et al. [140] & Deep learning & $\begin{array}{l}\text { Detection and characterization of FLL (benign vs. malignant) } \\
\text { Training ( } n=367 \text { patients): } \\
\text { - } \quad \text { Detection AUROC }=0.935 \\
\text { - } \quad \text { Characterization AUROC }=0.916 \\
\text { Test }(n=177 \text { patients): } \\
\text { - } \quad \text { AUROC }=0.891 \text { for } 7 \text { different tasks }\end{array}$ \\
\hline
\end{tabular}


Taking into consideration all the aforementioned studies, our opinion is that AI can dramatically improve the US detection of NAFLD and NAFLD-associated pathological entities, such as cirrhosis and HCC, through DL algorithms.

\subsection{Advantages and Pitfalls of Future AI-Based Solutions}

AI techniques present a number of advantages when they are employed. The diagnostic accuracy of a number of pathologies can greatly increase, which can be translated into a better patient survival in the case of early HCC detection. Our paper has identified recent studies that demonstrate the wide potential of DL algorithms in identifying NAFLD and NAFLD-related HCC [141]. We also highlight the increase in productivity and the improvement in the clinical decision making, which essentially translates in better patient satisfaction.

However, there are different elements that can hinder the development of ML solutions and currently limit their applicability in US medical imaging. In order to achieve good learning performance with deep learning, there is a need for large sets of data during the training process from which the algorithms "learn", which may currently be unavailable. For the supervised methods, the experts would have to swift through massive datasets and manually add annotations for the specific task, posing a real question of how to train such a model in a cost-effective and time-effective manner. Furthermore, there are several US-related features that can hamper the learning power of the AI: the artifacts in B-mode liver ultrasound (e.g., acoustic enhancement, comet tail, mirror image) or in Doppler mode (such as aliasing phenomenon or blooming artifact) must be recognized and not mistakenly diagnosed by the computer as pathologic. On the other hand, the US parameters (gainbrightness, depth, TGC curve, field of view) and the selection of probes must also be taken into consideration. Therefore, because of the variables related to the US machine as well as to the patient, the need for standardization is vital in order to achieve good results.

Eventually, there are potential biases that need to be considered before integrating AI in clinical practice. In the "anchoring effect", the operator tends to make an interpretation in relation with the initial reference and can get biased in the decision making [142]. The second bias is one that could occur in systems based on supervised learning and is called the "bandwagon effect". Knowing that the automated decision is based on a large collection of annotations, the operators tend to position their opinion with the algorithm [143].

Even if the medical imaging could benefit from the developments in computer science, mainly $\mathrm{CNN}$, there is still a need to standardize the evaluator potential in order to achieve the best possible results. The constant evolution of the automated systems shines a bright light towards the future of ultrasound imaging.

\section{Concluding Remarks}

The silent progression of NAFLD towards NAFLD-related HCC prompts for accurate disease-specific surveillance tools that present a high accuracy. Ultrasound-based methods are currently the epicenter of NAFLD evaluation, with B-mode US being the first-line examination in high clinical NAFLD suspicion patients.

US-based methods are a powerful addition to the clinical examination in NAFLD patients, providing qualitative, quantitative, or both qualitative-quantitative information in NAFLD, depending on the technique used. Conventional B-mode US is a broadly available, cost-effective, non-invasive method that returns only qualitative-subjective information and has a reported sensitivity of $85 \%$ and $95 \%$ specificity for detecting moderate to severe steatosis, but lacks accuracy in the evaluation of mild steatosis. Furthermore, conventional B-mode US can identify focal liver lesions, but cannot make an in-depth characterization; malignancy is suspected in large focal lesions with heterogeneous echostructure and signs of parenchymal distortion. Doppler blood flow evaluation can identify a central or peritumoral hypervascularity, basket pattern, or the presence of pulsatile afferent flow signal with a concomitant constant efferent flow, which are suggestive of HCC but not definitive. Although these US techniques 
are not the first-line HCC diagnostic methods, they remain important first-line screening and surveillance tools. In regard to CEUS, the add-on of UCAs has rendered possible the further characterization of FLLs by adding a new real-time quantitative assessment into the equation. As an accurate and cost-effective imaging modality for hepatic lesion evaluation, CEUS provides the HCC diagnosis through the standardized LI-RADS score and the characteristic arterial phase hyperenhancement followed by mild washout with late onset in the portal/late phase. The use of the current UCAs and US contrast-specific techniques has brought CEUS to a similar performance to CT and MRI for the characterizing focal liver lesions. In addition, compared to dynamic CT and MRI, US can be performed in real time, is less expensive, and has no associated nephrotoxicity or ionizing radiation.

The current paper also underlines the wide potential of Artificial Intelligence-based methods, with a focus on deep learning algorithms, in the NAFLD and NAFLD-related HCC's US images analysis. The literature search has identified a number of studies focused on NAFLD and NAFLD-related HCC that prove an increase in the diagnostic accuracy of these methods, when deep learning methods are employed. Our opinion is that AI could potentially be a game changer that widens the power of US based methods and, finally, benefits the patient by the early detection of NAFLD-related HCC.

Author Contributions: Conceptualization, all authors; writing-all authors; writing-review and editing, all authors; critically revising-M.L.-P. and M.F.; supervision, M.L.-P.; project administration, M.L.-P. All authors have read and agreed to the published version of the manuscript.

Funding: This research received no external funding.

Acknowledgments: The authors would like to thank Horatiu Florea for providing an insightful view upon the Artificial Intelligence section on the present paper, as well as for the design of the Graphical Abstract.

Conflicts of Interest: The authors declare no conflict of interest.

\section{References}

1. Estes, C.; Razavi, H.; Loomba, R.; Younossi, Z.; Sanyal, A.J. Modeling the epidemic of nonalcoholic fatty liver disease demonstrates an exponential increase in burden of disease. Hepatology 2018, 67, 123-133. [CrossRef]

2. Younossi, Z.M. Non-alcoholic fatty liver disease-A global public health perspective. J. Hepatol. 2019, 70, 531-544. [CrossRef] [PubMed]

3. Singh, S.; Muir, A.J.; Dieterich, D.T.; Falck-Ytter, Y.T. American Gastroenterological Association Institute Technical Review on the Role of Elastography in Chronic Liver Diseases. Gastroenterology 2017, 152, 1544-1577. [CrossRef] [PubMed]

4. Maher, J.J.; Schattenberg, J.M. Nonalcoholic Fatty Liver Disease in 2020. Gastroenterology 2020, 158, 1849-1850. [CrossRef] [PubMed]

5. Papatheodoridi, M.; Cholongitas, E. Diagnosis of Non-alcoholic Fatty Liver Disease (NAFLD): Current Concepts. Curr. Pharm. Des. 2018, 24, 4574-4586. [CrossRef] [PubMed]

6. Leoni, S.; Tovoli, F.; Napoli, L.; Serio, I.; Ferri, S.; Bolondi, L. Current guidelines for the management of non-alcoholic fatty liver disease: A systematic review with comparative analysis. World J. Gastroenterol. 2018, 24, 3361-3373. [CrossRef]

7. Maurice, J.; Manousou, P. Non-alcoholic fatty liver disease. Clin. Med. 2018, 18, 245-250. [CrossRef]

8. Chalasani, N.; Younossi, Z.; Lavine, J.E.; Charlton, M.; Cusi, K.; Rinella, M.; Harrison, S.A.; Brunt, E.M.; Sanyal, A.J. The diagnosis and management of nonalcoholic fatty liver disease: Practice guidance from the American Association for the Study of Liver Diseases. Hepatology 2018, 67, 328-357. [CrossRef]

9. Younossi, Z.M.; Koenig, A.B.; Abdelatif, D.; Fazel, Y.; Henry, L.; Wymer, M. Global epidemiology of nonalcoholic fatty liver disease-Meta-analytic assessment of prevalence, incidence, and outcomes. Hepatology 2016, 64, 73-84. [CrossRef]

10. Caines, A.; Selim, R.; Salgia, R. The Changing Global Epidemiology of Hepatocellular Carcinoma. Clin. Liv. Dis. 2020, $24,535-547$. [CrossRef]

11. Mittal, S.; El-Serag, H.B.; Sada, Y.H.; Kanwal, F.; Duan, Z.; Temple, S.; May, S.B.; Kramer, J.R.; Richardson, P.A.; Davila, J.A. Hepatocellular Carcinoma in the Absence of Cirrhosis in United States Veterans is Associated with Nonalcoholic Fatty Liver Disease. Clin. Gastroenterol. Hepatol. 2016, 14, 124-131.e1. [CrossRef] [PubMed]

12. Golabi, P.; Rhea, L.; Henry, L.; Younossi, Z.M. Hepatocellular carcinoma and non-alcoholic fatty liver disease. Hepatol. Int. 2019, 13, 688-694. [CrossRef]

13. Koeckerling, D.; Tomlinson, J.W.; Cobbold, J.F. Fighting liver fat. Endocr. Connect. 2020, 9, R173-R186. [CrossRef]

14. Lupsor-Platon, M.; Serban, T.; Silion, A.I.; Tirpe, A.; Florea, M. Hepatocellular Carcinoma and Non-Alcoholic Fatty Liver Disease: A Step Forward for Better Evaluation Using Ultrasound Elastography. Cancers 2020, 12, 2778. [CrossRef] [PubMed] 
15. Pocha, C.; Dieperink, E.; McMaken, K.A.; Knott, A.; Thuras, P.; Ho, S.B. Surveillance for hepatocellular cancer with ultrasonography vs. computed tomography-A randomised study. Aliment. Pharmacol. Ther. 2013, 38, 303-312. [CrossRef]

16. Singal, A.; Volk, M.L.; Waljee, A.; Salgia, R.; Higgins, P.; Rogers, M.A.; Marrero, J.A. Meta-analysis: Surveillance with ultrasound for early-stage hepatocellular carcinoma in patients with cirrhosis. Aliment. Pharmacol. Ther. 2009, 30, 37-47. [CrossRef]

17. Samoylova, M.L.; Mehta, N.; Roberts, J.P.; Yao, F.Y. Predictors of Ultrasound Failure to Detect Hepatocellular Carcinoma. Liver Transpl. 2018, 24, 1171-1177. [CrossRef]

18. Llovet, J.M.; Zucman-Rossi, J.; Pikarsky, E.; Sangro, B.; Schwartz, M.; Sherman, M.; Gores, G. Hepatocellular carcinoma. Nat. Rev. Dis. Primers. 2016, 2, 16018. [CrossRef]

19. Marrero, J.A.; Kulik, L.M.; Sirlin, C.B.; Zhu, A.X.; Finn, R.S.; Abecassis, M.M.; Roberts, L.R.; Heimbach, J.K. Diagnosis, Staging, and Management of Hepatocellular Carcinoma: 2018 Practice Guidance by the American Association for the Study of Liver Diseases. Hepatology 2018, 68, 723-750. [CrossRef] [PubMed]

20. Zhang, Y.N.; Fowler, K.J.; Hamilton, G.; Cui, J.Y.; Sy, E.Z.; Balanay, M.; Hooker, J.C.; Szeverenyi, N.; Sirlin, C.B. Liver fat imaging-a clinical overview of ultrasound, CT, and MR imaging. Br. J. Radiol. 2018, 91, 20170959. [CrossRef] [PubMed]

21. Jennison, E.; Patel, J.; Scorletti, E.; Byrne, C.D. Diagnosis and management of non-alcoholic fatty liver disease. Postgrad. Med. J. 2019, 95, 314-322. [CrossRef]

22. Hernaez, R.; Lazo, M.; Bonekamp, S.; Kamel, I.; Brancati, F.L.; Guallar, E.; Clark, J.M. Diagnostic accuracy and reliability of ultrasonography for the detection of fatty liver: A meta-analysis. Hepatology 2011, 54, 1082-1090. [CrossRef]

23. Gaiani, S.; Avogaro, A.; Bombonato, G.C.; Bolognesi, M.; Amor, F.; Vigili de Kreutzenberg, S.; Guarneri, G.; Sacerdoti, D. Nonalcoholic fatty liver disease (NAFLD) in nonobese patients with diabetes: Prevalence and relationships with hemodynamic alterations detected with Doppler sonography. J. Ultrasound. 2009, 12, 1-5. [CrossRef]

24. Castera, L.; Friedrich-Rust, M.; Loomba, R. Noninvasive Assessment of Liver Disease in Patients With Nonalcoholic Fatty Liver Disease. Gastroenterology 2019, 156, 1264-1281. [CrossRef]

25. Abd El-Kader, S.M.; El-Den Ashmawy, E.M. Non-alcoholic fatty liver disease: The diagnosis and management. World J. Hepatol. 2015, 7, 846-858. [CrossRef] [PubMed]

26. Lee, D.H. Imaging evaluation of non-alcoholic fatty liver disease: Focused on quantification. Clin. Mol. Hepatol. 2017, 23, 290-301. [CrossRef] [PubMed]

27. Kim, S.H.; Lee, J.M.; Kim, J.H.; Kim, K.G.; Han, J.K.; Lee, K.H.; Park, S.H.; Yi, N.J.; Suh, K.S.; An, S.K.; et al. Appropriateness of a donor liver with respect to macrosteatosis: Application of artificial neural networks to US images-initial experience. Radiology 2005, 234, 793-803. [CrossRef]

28. Wang, C.C.; Hsieh, T.C.; Tseng, T.C.; Wang, P.C.; Hsu, C.S.; Lin, H.H.; Wang, L.Y.; Kao, J.H. Factors affecting the diagnostic accuracy of ultrasonography in assessing the severity of hepatic steatosis. J. Formos. Med. Assoc. 2014, 113, 249-254. [CrossRef] [PubMed]

29. Dasarathy, S.; Dasarathy, J.; Khiyami, A.; Joseph, R.; Lopez, R.; McCullough, A.J. Validity of real time ultrasound in the diagnosis of hepatic steatosis: A prospective study. J. Hepatol. 2009, 51, 1061-1067. [CrossRef]

30. Lupsor-Platon, M.; Stefanescu, H.; Muresan, D.; Florea, M.; Szasz, M.E.; Maniu, A.; Badea, R. Noninvasive assessment of liver steatosis using ultrasound methods. Med. Ultrason. 2014, 16, 236-245. [CrossRef] [PubMed]

31. Pirmoazen, A.M.; Khurana, A.; El Kaffas, A.; Kamaya, A. Quantitative ultrasound approaches for diagnosis and monitoring hepatic steatosis in nonalcoholic fatty liver disease. Theranostics 2020, 10, 4277-4289. [CrossRef] [PubMed]

32. Xia, M.F.; Yan, H.M.; He, W.Y.; Li, X.M.; Li, C.L.; Yao, X.Z.; Li, R.K.; Zeng, M.S.; Gao, X. Standardized ultrasound hepatic/renal ratio and hepatic attenuation rate to quantify liver fat content: An improvement method. Obesity 2012, 20, 444-452. [CrossRef]

33. Ballestri, S.; Nascimbeni, F.; Lugari, S.; Lonardo, A.; Francica, G. A critical appraisal of the use of ultrasound in hepatic steatosis. Expert Rev. Gastroenterol. Hepatol. 2019, 13, 667-681. [CrossRef] [PubMed]

34. Kwon, H.J.; Kim, K.W.; Jung, J.H.; Choi, S.H.; Jeong, W.K.; Kim, B.; Song, G.W.; Lee, S.G. Noninvasive quantitative estimation of hepatic steatosis by ultrasound: A comparison of the hepato-renal index and ultrasound attenuation index. Med. Ultrason. 2016, 18, 431-437. [CrossRef] [PubMed]

35. Karcaaltincaba, M.; Akhan, O. Imaging of hepatic steatosis and fatty sparing. Eur. J. Radiol. 2007, 61, 33-43. [CrossRef] [PubMed]

36. Venkatesh, S.K.; Hennedige, T.; Johnson, G.B.; Hough, D.M.; Fletcher, J.G. Imaging patterns and focal lesions in fatty liver: A pictorial review. Abdom. Radiol. 2017, 42, 1374-1392. [CrossRef] [PubMed]

37. Tobari, M.; Hashimoto, E.; Yatsuji, S.; Torii, N.; Shiratori, K. Imaging of nonalcoholic steatohepatitis: Advantages and pitfalls of ultrasonography and computed tomography. Intern. Med. 2009, 48, 739-746. [CrossRef] [PubMed]

38. Bril, F.; Ortiz-Lopez, C.; Lomonaco, R.; Orsak, B.; Freckleton, M.; Chintapalli, K.; Hardies, J.; Lai, S.; Solano, F.; Tio, F.; et al. Clinical value of liver ultrasound for the diagnosis of nonalcoholic fatty liver disease in overweight and obese patients. Liver Int. 2015, 35, 2139-2146. [CrossRef]

39. Charatcharoenwitthaya, P.; Lindor, K.D. Role of radiologic modalities in the management of non-alcoholic steatohepatitis. Clin. Liver Dis. 2007, 11, 37-54. [CrossRef]

40. Saadeh, S.; Younossi, Z.M.; Remer, E.M.; Gramlich, T.; Ong, J.P.; Hurley, M.; Mullen, K.D.; Cooper, J.N.; Sheridan, M.J. The utility of radiological imaging in nonalcoholic fatty liver disease. Gastroenterology 2002, 123, 745-750. [CrossRef]

41. Milic, S.; Lulic, D.; Stimac, D. Non-alcoholic fatty liver disease and obesity: Biochemical, metabolic and clinical presentations. World J. Gastroenterol. 2014, 20, 9330-9337. [CrossRef] 
42. de Moura Almeida, A.; Cotrim, H.P.; Barbosa, D.B.; de Athayde, L.G.; Santos, A.S.; Bitencourt, A.G.; de Freitas, L.A.; Rios, A.; Alves, E. Fatty liver disease in severe obese patients: Diagnostic value of abdominal ultrasound. World J. Gastroenterol. 2008, 14, 1415-1418. [CrossRef]

43. European Association for the Study of the Liver. EASL Clinical Practice Guidelines: Management of hepatocellular carcinoma. J. Hepatol. 2018, 69, 182-236. [CrossRef]

44. Choi, H.H.; Rodgers, S.K.; Fetzer, D.T.; Wasnik, A.P.; Millet, J.D.; Morgan, T.A.; Dawkins, A.; Gabriel, H.; Kamaya, A. Ultrasound Liver Imaging Reporting and Data System (US LI-RADS): An Overview with Technical and Practical Applications. Acad. Radiol. 2020. [CrossRef]

45. Morgan, T.A.; Maturen, K.E.; Dahiya, N.; Sun, M.R.M.; Kamaya, A.; American College of Radiology Ultrasound Liver, I.; Reporting Data System Working, G. US LI-RADS: Ultrasound liver imaging reporting and data system for screening and surveillance of hepatocellular carcinoma. Abdom. Radiol. 2018, 43, 41-55. [CrossRef] [PubMed]

46. Tchelepi, H.; Ralls, P.W.; Radin, R.; Grant, E. Sonography of diffuse liver disease. J. Ultrasound Med. 2002, 21, 1023-1032, quiz 1033-1024. [CrossRef] [PubMed]

47. Minami, Y.; Kudo, M. Hepatic malignancies: Correlation between sonographic findings and pathological features. World J. Radiol. 2010, 2, 249-256. [CrossRef]

48. Tchelepi, H.; Ralls, P.W. Ultrasound of focal liver masses. Ultrasound Q. 2004, 20, 155-169. [CrossRef]

49. Harvey, C.J.; Albrecht, T. Ultrasound of focal liver lesions. Eur. Radiol. 2001, 11, 1578-1593. [CrossRef] [PubMed]

50. Terminology and Diagnostic Criteria Committee, Japan Society of Ultrasonics in Medicine. Ultrasound diagnostic criteria for hepatic tumors. J. Med. Ultrason. 2014, 41, 113-123. [CrossRef]

51. Tochio, H.; Kudo, M. Afferent and efferent vessels of premalignant and overt hepatocellular carcinoma: Observation by color Doppler imaging. Intervirology 2004, 47, 144-153. [CrossRef] [PubMed]

52. Kudo, M.; Tochio, H.; Zhou, P. Differentiation of hepatic tumors by color Doppler imaging: Role of the maximum velocity and the pulsatility index of the intratumoral blood flow signal. Intervirology 2004, 47, 154-161. [CrossRef]

53. Salvatore, V.; Bolondi, L. Clinical impact of ultrasound-related techniques on the diagnosis of focal liver lesions. Liver Cancer 2012, 1, 238-246. [CrossRef] [PubMed]

54. Wu, S.; Tu, R.; Liu, G.; Huang, L.; Guan, Y.; Zheng, E. Focal fatty sparing usually does not arise in preexisting nonalcoholic diffuse homogeneous fatty liver. J. Ultrasound Med. 2014, 33, 1447-1452. [CrossRef] [PubMed]

55. Lupsor, M.; Badea, R. Imaging diagnosis and quantification of hepatic steatosis: Is it an accepted alternative to needle biopsy? Rom. J. Gastroenterol. 2005, 14, 419-425.

56. Tzartzeva, K.; Obi, J.; Rich, N.E.; Parikh, N.D.; Marrero, J.A.; Yopp, A.; Waljee, A.K.; Singal, A.G. Surveillance Imaging and Alpha Fetoprotein for Early Detection of Hepatocellular Carcinoma in Patients With Cirrhosis: A Meta-analysis. Gastroenterology 2018, 154, 1706-1718.e1. [CrossRef] [PubMed]

57. Lencioni, R.; Della Pina, C.; Crocetti, L.; Bozzi, E.; Cioni, D. Clinical management of focal liver lesions: The key role of real-time contrast-enhanced US. Eur. Radiol. 2007, 17 (Suppl. 6), F73-F79. [CrossRef]

58. Claudon, M.; Dietrich, C.F.; Choi, B.I.; Cosgrove, D.O.; Kudo, M.; Nolsoe, C.P.; Piscaglia, F.; Wilson, S.R.; Barr, R.G.; Chammas, M.C.; et al. Guidelines and good clinical practice recommendations for Contrast Enhanced Ultrasound (CEUS) in the liverUpdate 2012: A WFUMB-EFSUMB initiative in cooperation with representatives of AFSUMB, AIUM, ASUM, FLAUS and ICUS. Ultrasound Med. Biol. 2013, 39, 187-210. [CrossRef] [PubMed]

59. Wilson, S.R.; Lyshchik, A.; Piscaglia, F.; Cosgrove, D.; Jang, H.J.; Sirlin, C.; Dietrich, C.F.; Kim, T.K.; Willmann, J.K.; Kono, Y. CEUS LI-RADS: Algorithm, implementation, and key differences from CT/MRI. Abdom. Radiol. 2018, 43, 127-142. [CrossRef]

60. Dietrich, C.F.; Averkiou, M.; Nielsen, M.B.; Barr, R.G.; Burns, P.N.; Calliada, F.; Cantisani, V.; Choi, B.; Chammas, M.C.; Clevert, D.A.; et al. How to perform Contrast-Enhanced Ultrasound (CEUS). Ultrasound Int. Open 2018, 4, E2-E15. [CrossRef] [PubMed]

61. Dietrich, C.F.; Nolsoe, C.P.; Barr, R.G.; Berzigotti, A.; Burns, P.N.; Cantisani, V.; Chammas, M.C.; Chaubal, N.; Choi, B.I.; Clevert, D.A.; et al. Guidelines and Good Clinical Practice Recommendations for Contrast Enhanced Ultrasound (CEUS) in the Liver-Update 2020_WFUMB in Cooperation with EFSUMB, AFSUMB, AIUM, and FLAUS. Ultraschall Med. 2020. [CrossRef]

62. Cosgrove, D.; Harvey, C. Clinical uses of microbubbles in diagnosis and treatment. Med. Biol. Eng. Comput. 2009, 47, 813-826. [CrossRef] [PubMed]

63. Kudo, M.; Ueshima, K.; Osaki, Y.; Hirooka, M.; Imai, Y.; Aso, K.; Numata, K.; Kitano, M.; Kumada, T.; Izumi, N.; et al. B-Mode Ultrasonography versus Contrast-Enhanced Ultrasonography for Surveillance of Hepatocellular Carcinoma: A Prospective Multicenter Randomized Controlled Trial. Liver Cancer 2019, 8, 271-280. [CrossRef]

64. Ertle, J.; Dechene, A.; Sowa, J.P.; Penndorf, V.; Herzer, K.; Kaiser, G.; Schlaak, J.F.; Gerken, G.; Syn, W.K.; Canbay, A. Non-alcoholic fatty liver disease progresses to hepatocellular carcinoma in the absence of apparent cirrhosis. Int. J. Cancer 2011, 128, $2436-2443$. [CrossRef]

65. Carvalho, C.F.; Chammas, M.C.; Souza de Oliveira, C.P.; Cogliati, B.; Carrilho, F.J.; Cerri, G.G. Elastography and Contrastenhanced Ultrasonography in the Early Detection of Hepatocellular Carcinoma in an Experimental Model of Nonalcoholic Steatohepatitis. J. Clin. Exp. Hepatol. 2013, 3, 96-101. [CrossRef] [PubMed]

66. Vijayaraghavan, G.R.; David, S.; Bermudez-Allende, M.; Sarwat, H. Imaging-guided Parenchymal Liver Biopsy: How We Do It. J Clin. Imaging Sci. 2011, 1, 30. [CrossRef]

67. Tanaka, H. Current role of ultrasound in the diagnosis of hepatocellular carcinoma. J. Med. Ultrason. 2020, 47, 239-255. [CrossRef] 
68. Friedrich-Rust, M.; Klopffleisch, T.; Nierhoff, J.; Herrmann, E.; Vermehren, J.; Schneider, M.D.; Zeuzem, S.; Bojunga, J. ContrastEnhanced Ultrasound for the differentiation of benign and malignant focal liver lesions: A meta-analysis. Liver Int. 2013, 33, 739-755. [CrossRef]

69. Romanini, L.; Passamonti, M.; Aiani, L.; Cabassa, P.; Raieli, G.; Montermini, I.; Martegani, A.; Grazioli, L.; Calliada, F. Economic assessment of contrast-enhanced ultrasonography for evaluation of focal liver lesions: A multicentre Italian experience. Eur. Radiol. 2007, 17 (Suppl. 6), F99-F106. [CrossRef]

70. Smajerova, M.; Petrasova, H.; Little, J.; Ovesna, P.; Andrasina, T.; Valek, V.; Nemcova, E.; Miklosova, B. Contrast-enhanced ultrasonography in the evaluation of incidental focal liver lesions: A cost-effectiveness analysis. World J. Gastroenterol. 2016, 22, 8605-8614. [CrossRef]

71. Kim, T.H.; Yoon, J.H.; Lee, J.M. Emerging Role of Hepatobiliary Magnetic Resonance Contrast Media and Contrast-Enhanced Ultrasound for Noninvasive Diagnosis of Hepatocellular Carcinoma: Emphasis on Recent Updates in Major Guidelines. Korean J. Radiol. 2019, 20, 863-879. [CrossRef]

72. Konno, K.; Ishida, H.; Sato, M.; Komatsuda, T.; Ishida, J.; Naganuma, H.; Hamashima, Y.; Watanabe, S. Liver tumors in fatty liver: Difficulty in ultrasonographic interpretation. Abdom. Imaging 2001, 26, 487-491. [CrossRef]

73. Farrell, G.C.; Teoh, N.C.; McCuskey, R.S. Hepatic microcirculation in fatty liver disease. Anat. Rec. 2008, 291, 684-692. [CrossRef]

74. Cocciolillo, S.; Parruti, G.; Marzio, L. CEUS and Fibroscan in non-alcoholic fatty liver disease and non-alcoholic steatohepatitis. World J. Hepatol. 2014, 6, 496-503. [CrossRef] [PubMed]

75. Pandit, H.; Tinney, J.P.; Li, Y.; Cui, G.; Li, S.; Keller, B.B.; Martin, R.C.G., 2nd. Utilizing Contrast-Enhanced Ultrasound Imaging for Evaluating Fatty Liver Disease Progression in Pre-clinical Mouse Models. Ultrasound Med. Biol. 2019, 45, 549-557. [CrossRef]

76. Tsujimoto, T.; Kawaratani, H.; Kitazawa, T.; Hirai, T.; Ohishi, H.; Kitade, M.; Yoshiji, H.; Uemura, M.; Fukui, H. Decreased phagocytic activity of Kupffer cells in a rat nonalcoholic steatohepatitis model. World J. Gastroenterol. 2008, 14, 6036-6043. [CrossRef]

77. Blomley, M.J.; Lim, A.K.; Harvey, C.J.; Patel, N.; Eckersley, R.J.; Basilico, R.; Heckemann, R.; Urbank, A.; Cosgrove, D.O.; Taylor-Robinson, S.D. Liver microbubble transit time compared with histology and Child-Pugh score in diffuse liver disease: A cross sectional study. Gut 2003, 52, 1188-1193. [CrossRef] [PubMed]

78. Nasr, P.; Hilliges, A.; Thorelius, L.; Kechagias, S.; Ekstedt, M. Contrast-enhanced ultrasonography could be a non-invasive method for differentiating none or mild from severe fibrosis in patients with biopsy proven non-alcoholic fatty liver disease. Scand. J. Gastroenterol. 2016, 51, 1126-1132. [CrossRef] [PubMed]

79. Li, N.; Ding, H.; Fan, P.; Lin, X.; Xu, C.; Wang, W.; Xu, Z.; Wang, J. Intrahepatic transit time predicts liver fibrosis in patients with chronic hepatitis B: Quantitative assessment with contrast-enhanced ultrasonography. Ultrasound Med. Biol. 2010, 36, 1066-1075. [CrossRef] [PubMed]

80. Lim, A.K.; Taylor-Robinson, S.D.; Patel, N.; Eckersley, R.J.; Goldin, R.D.; Hamilton, G.; Foster, G.R.; Thomas, H.C.; Cosgrove, D.O.; Blomley, M.J. Hepatic vein transit times using a microbubble agent can predict disease severity non-invasively in patients with hepatitis C. Gut 2005, 54, 128-133. [CrossRef] [PubMed]

81. Topal, N.B.; Orcan, S.; Sigirli, D.; Orcan, G.; Eritmen, U. Effects of fat accumulation in the liver on hemodynamic variables assessed by Doppler ultrasonography. J. Clin. Ultrasound 2015, 43, 26-33. [CrossRef] [PubMed]

82. Balasubramanian, P.; Boopathy, V.; Govindasamy, E.; Venkatesh, B.P. Assessment of Portal Venous and Hepatic Artery Haemodynamic Variation in Non-Alcoholic Fatty Liver Disease (NAFLD) Patients. J. Clin. Diagn. Res. 2016, 10, TC07-TC10. [CrossRef]

83. Korean Liver Cancer Study Group; National Cancer Center, Korea. 2014 Korean Liver Cancer Study Group-National Cancer Center Korea practice guideline for the management of hepatocellular carcinoma. Korean J. Radiol. 2015, 16, 465-522. [CrossRef]

84. Bruix, J.; Sherman, M.; Llovet, J.M.; Beaugrand, M.; Lencioni, R.; Burroughs, A.K.; Christensen, E.; Pagliaro, L.; Colombo, M.; Rodes, J.; et al. Clinical management of hepatocellular carcinoma. Conclusions of the Barcelona-2000 EASL conference. European Association for the Study of the Liver. J. Hepatol. 2001, 35, 421-430. [CrossRef]

85. Seitz, K.; Strobel, D.; Bernatik, T.; Blank, W.; Friedrich-Rust, M.; Herbay, A.; Dietrich, C.F.; Strunk, H.; Kratzer, W.; Schuler, A. Contrast-Enhanced Ultrasound (CEUS) for the characterization of focal liver lesions-Prospective comparison in clinical practice: CEUS vs. CT (DEGUM multicenter trial). Parts of this manuscript were presented at the Ultrasound Dreilandertreffen 2008, Davos. Ultraschall Med. 2009, 30, 383-389. [CrossRef] [PubMed]

86. Strobel, D.; Bernatik, T.; Blank, W.; Schuler, A.; Greis, C.; Dietrich, C.F.; Seitz, K. Diagnostic accuracy of CEUS in the differential diagnosis of small $(</=20 \mathrm{~mm})$ and subcentimetric $(</=10 \mathrm{~mm})$ focal liver lesions in comparison with histology. Results of the DEGUM multicenter trial. Ultraschall Med. 2011, 32, 593-597. [CrossRef]

87. Strobel, D.; Seitz, K.; Blank, W.; Schuler, A.; Dietrich, C.; von Herbay, A.; Friedrich-Rust, M.; Kunze, G.; Becker, D.; Will, U.; et al. Contrast-enhanced ultrasound for the characterization of focal liver lesions-diagnostic accuracy in clinical practice (DEGUM multicenter trial). Ultraschall Med. 2008, 29, 499-505. [CrossRef]

88. Sporea, I.; Badea, R.; Popescu, A.; Sparchez, Z.; Sirli, R.L.; Danila, M.; Sandulescu, L.; Bota, S.; Calescu, D.P.; Nedelcu, D.; et al. Contrast-enhanced ultrasound (CEUS) for the evaluation of focal liver lesions-A prospective multicenter study of its usefulness in clinical practice. Ultraschall Med. 2014, 35, 259-266. [CrossRef]

89. Trillaud, H.; Bruel, J.M.; Valette, P.J.; Vilgrain, V.; Schmutz, G.; Oyen, R.; Jakubowski, W.; Danes, J.; Valek, V.; Greis, C. Characterization of focal liver lesions with SonoVue-enhanced sonography: International multicenter-study in comparison to CT and MRI. World J. Gastroenterol. 2009, 15, 3748-3756. [CrossRef] [PubMed] 
90. Jiang, H.Y.; Chen, J.; Xia, C.C.; Cao, L.K.; Duan, T.; Song, B. Noninvasive imaging of hepatocellular carcinoma: From diagnosis to prognosis. World J. Gastroenterol. 2018, 24, 2348-2362. [CrossRef] [PubMed]

91. Tanaka, H.; Iijima, H.; Nouso, K.; Aoki, N.; Iwai, T.; Takashima, T.; Sakai, Y.; Aizawa, N.; Iwata, K.; Ikeda, N.; et al. Costeffectiveness analysis on the surveillance for hepatocellular carcinoma in liver cirrhosis patients using contrast-enhanced ultrasonography. Hepatol. Res. 2012, 42, 376-384. [CrossRef] [PubMed]

92. Auer, T.A.; Fischer, T.; Garcia, S.R.M.; Penzkofer, T.; Jung, E.M.; Hamm, B.; Lerchbaumer, M.H. Value of contrast-enhanced ultrasound (CEUS) in Focal Liver Lesions (FLL) with inconclusive findings on cross-sectional imaging. Clin. Hemorheol. Microcirc. 2020, 74, 327-339. [CrossRef]

93. Sawatzki, M.; Meyenberger, C.; Brand, S.; Semela, D. Contrast-enhanced ultrasound (CEUS) has excellent diagnostic accuracy in differentiating focal liver lesions: Results from a Swiss tertiary gastroenterological centre. Swiss. Med. Wkly. 2019, 149, w20087. [CrossRef]

94. Zhang, J.; Yu, Y.; Li, Y.; Wei, L. Diagnostic value of contrast-enhanced ultrasound in hepatocellular carcinoma: A meta-analysis with evidence from 1998 to 2016. Oncotarget 2017, 8, 75418-75426. [CrossRef]

95. Yue, W.W.; Wang, S.; Xu, H.X.; Sun, L.P.; Guo, L.H.; Bo, X.W.; Li, X.L.; Zhao, C.K.; Wang, D.; Liu, B.J. Parametric imaging with contrast-enhanced ultrasound for differentiating hepatocellular carcinoma from metastatic liver cancer. Clin. Hemorheol. Microcirc. 2016, 64, 177-188. [CrossRef] [PubMed]

96. Deng, H.; Shi, H.; Lei, J.; Hu, Y.; Li, G.; Wang, C. A meta-analysis of contrast-enhanced ultrasound for small hepatocellular carcinoma diagnosis. J. Cancer Res. Ther. 2016, 12, C274-C276. [CrossRef] [PubMed]

97. Xie, L.; Guang, Y.; Ding, H.; Cai, A.; Huang, Y. Diagnostic value of contrast-enhanced ultrasound, computed tomography and magnetic resonance imaging for focal liver lesions: A meta-analysis. Ultrasound Med. Biol. 2011, 37, 854-861. [CrossRef] [PubMed]

98. Yang, D.; Li, R.; Zhang, X.H.; Tang, C.L.; Ma, K.S.; Guo, D.Y.; Yan, X.C. Perfusion Characteristics of Hepatocellular Carcinoma at Contrast-enhanced Ultrasound: Influence of the Cellular differentiation, the Tumor Size and the Underlying Hepatic Condition. Sci. Rep. 2018, 8, 4713. [CrossRef]

99. Iavarone, M.; Sangiovanni, A.; Forzenigo, L.V.; Massironi, S.; Fraquelli, M.; Aghemo, A.; Ronchi, G.; Biondetti, P.; Roncalli, M.; Colombo, M. Diagnosis of hepatocellular carcinoma in cirrhosis by dynamic contrast imaging: The importance of tumor cell differentiation. Hepatology 2010, 52, 1723-1730. [CrossRef]

100. Boozari, B.; Soudah, B.; Rifai, K.; Schneidewind, S.; Vogel, A.; Hecker, H.; Hahn, A.; Schlue, J.; Dietrich, C.F.; Bahr, M.J.; et al. Grading of hypervascular hepatocellular carcinoma using late phase of contrast enhanced sonography-A prospective study. Dig. Liver Dis. 2011, 43, 484-490. [CrossRef]

101. Nicolau, C.; Catala, V.; Vilana, R.; Gilabert, R.; Bianchi, L.; Sole, M.; Pages, M.; Bru, C. Evaluation of hepatocellular carcinoma using SonoVue, a second generation ultrasound contrast agent: Correlation with cellular differentiation. Eur. Radiol. 2004, 14, 1092-1099. [CrossRef]

102. von Herbay, A.; Vogt, C.; Westendorff, J.; Haussinger, D.; Gregor, M. Correlation between SonoVue enhancement in CEUS, HCC differentiation and HCC diameter: Analysis of 130 patients with hepatocellular carcinoma (HCC). Ultraschall Med. 2009, 30, 544-550. [CrossRef] [PubMed]

103. Matsui, O.; Kobayashi, S.; Sanada, J.; Kouda, W.; Ryu, Y.; Kozaka, K.; Kitao, A.; Nakamura, K.; Gabata, T. Hepatocelluar nodules in liver cirrhosis: Hemodynamic evaluation (angiography-assisted CT) with special reference to multi-step hepatocarcinogenesis. Abdom. Imaging 2011, 36, 264-272. [CrossRef] [PubMed]

104. Jang, H.J.; Kim, T.K.; Burns, P.N.; Wilson, S.R. Enhancement patterns of hepatocellular carcinoma at contrast-enhanced US: Comparison with histologic differentiation. Radiology 2007, 244, 898-906. [CrossRef] [PubMed]

105. Piscaglia, F.; Wilson, S.R.; Lyshchik, A.; Cosgrove, D.; Dietrich, C.F.; Jang, H.J.; Kim, T.K.; Salvatore, V.; Willmann, J.K.; Sirlin, C.B.; et al. American College of Radiology Contrast Enhanced Ultrasound Liver Imaging Reporting and Data System (CEUS LI-RADS) for the diagnosis of Hepatocellular Carcinoma: A pictorial essay. Ultraschall Med. 2017, 38, 320-324. [CrossRef]

106. Kim, T.K.; Noh, S.Y.; Wilson, S.R.; Kono, Y.; Piscaglia, F.; Jang, H.J.; Lyshchik, A.; Dietrich, C.F.; Willmann, J.K.; Vezeridis, A.; et al. Contrast-enhanced ultrasound (CEUS) liver imaging reporting and data system (LI-RADS) 2017-A review of important differences compared to the CT/MRI system. Clin. Mol. Hepatol. 2017, 23, 280-289. [CrossRef]

107. Lyshchik, A.; Kono, Y.; Dietrich, C.F.; Jang, H.J.; Kim, T.K.; Piscaglia, F.; Vezeridis, A.; Willmann, J.K.; Wilson, S.R. Contrastenhanced ultrasound of the liver: Technical and lexicon recommendations from the ACR CEUS LI-RADS working group. Abdom. Radiol. 2018, 43, 861-879. [CrossRef]

108. Ferraioli, G.; Meloni, M.F. Contrast-enhanced ultrasonography of the liver using SonoVue. Ultrasonography 2018, 37, 25-35. [CrossRef]

109. Schellhaas, B.; Wildner, D.; Pfeifer, L.; Goertz, R.S.; Hagel, A.; Neurath, M.F.; Strobel, D. LI-RADS-CEUS-Proposal for a Contrast-Enhanced Ultrasound Algorithm for the Diagnosis of Hepatocellular Carcinoma in High-Risk Populations. Ultraschall Med. 2016, 37, 627-634. [CrossRef]

110. Kono, Y.; Lyshchik, A.; Cosgrove, D.; Dietrich, C.F.; Jang, H.J.; Kim, T.K.; Piscaglia, F.; Willmann, J.K.; Wilson, S.R.; Santillan, C.; et al. Contrast Enhanced Ultrasound (CEUS) Liver Imaging Reporting and Data System (LI-RADS(R)): The official version by the American College of Radiology (ACR). Ultraschall Med. 2017, 38, 85-86. [CrossRef]

111. Bartolotta, T.V.; Terranova, M.C.; Gagliardo, C.; Taibbi, A. CEUS LI-RADS: A pictorial review. Insights Imaging 2020, 11, 9. [CrossRef] 
112. Terzi, E.; Bonis, L.; Leoni, S.; Benevento, F.; Granito, A.; Tovoli, F.; Pini, P.; Bolondi, L.; Piscaglia, F. CEUS LI-RADS are effective in predicting the risk hepatocellular carcinoma of liver nodules. Dig. Liver Dis. 2017, 49, e22. [CrossRef]

113. Harris, P.S.; Hansen, R.M.; Gray, M.E.; Massoud, O.I.; McGuire, B.M.; Shoreibah, M.G. Hepatocellular carcinoma surveillance: An evidence-based approach. World J. Gastroenterol. 2019, 25, 1550-1559. [CrossRef] [PubMed]

114. Janica, J.; Ustymowicz, A.; Lukasiewicz, A.; Panasiuk, A.; Niemcunowicz-Janica, A.; Turecka-Kulesza, E.; Lebkowska, U. Comparison of contrast-enhanced ultrasonography with grey-scale ultrasonography and contrast-enhanced computed tomography in diagnosing focal fatty liver infiltrations and focal fatty sparing. Adv. Med. Sci. 2013, 58, 408-418. [CrossRef] [PubMed]

115. Numata, K.; Morimoto, M.; Ogura, T.; Sugimori, K.; Takebayashi, S.; Okada, M.; Tanaka, K. Ablation therapy guided by contrastenhanced sonography with Sonazoid for hepatocellular carcinoma lesions not detected by conventional sonography. J. Ultrasound Med. 2008, 27, 395-406. [CrossRef]

116. Numata, K.; Luo, W.; Morimoto, M.; Kondo, M.; Kunishi, Y.; Sasaki, T.; Nozaki, A.; Tanaka, K. Contrast enhanced ultrasound of hepatocellular carcinoma. World J. Radiol. 2010, 2, 68-82. [CrossRef]

117. Iurca, I.; Tirpe, A.; Zimta, A.A.; Moldovan, C.; Gulei, D.; Slaby, O.; Condorelli, G.; Berindan-Neagoe, I. Macrophages Interaction and MicroRNA Interplay in the Modulation of Cancer Development and Metastasis. Front. Immunol. 2020, 11, 870. [CrossRef]

118. Arita, J.; Hasegawa, K.; Takahashi, M.; Hata, S.; Shindoh, J.; Sugawara, Y.; Kokudo, N. Correlation between contrast-enhanced intraoperative ultrasound using Sonazoid and histologic grade of resected hepatocellular carcinoma. AJR Am. J. Roentgenol. 2011, 196, 1314-1321. [CrossRef]

119. Wu, M.; Li, L.; Wang, J.; Zhang, Y.; Guo, Q.; Li, X.; Zhang, X. Contrast-enhanced US for characterization of focal liver lesions: A comprehensive meta-analysis. Eur. Radiol. 2018, 28, 2077-2088. [CrossRef] [PubMed]

120. Borges, V.F.; Diniz, A.L.; Cotrim, H.P.; Rocha, H.L.; Andrade, N.B. Sonographic hepatorenal ratio: A noninvasive method to diagnose nonalcoholic steatosis. J. Clin. Ultrasound 2013, 41, 18-25. [CrossRef]

121. Webb, M.; Yeshua, H.; Zelber-Sagi, S.; Santo, E.; Brazowski, E.; Halpern, Z.; Oren, R. Diagnostic value of a computerized hepatorenal index for sonographic quantification of liver steatosis. AJR Am. J. Roentgenol. 2009, 192, 909-914. [CrossRef] [PubMed]

122. Lupsor, M.; Badea, R.; Nedevschi, S.; Mitrea, D.; Florea, M. Ultrasonography Contribution to Hepatic Steatosis Quantification. Possibilities of Improving this Method through Computerized Analysis of Ultrasonic Image. In Proceedings of the 2006 IEEE International Conference on Automation, Quality and Testing, Robotics, Cluj-Napora, Romania, 25-28 May 2006; pp. 478-483.

123. Wu, G.G.; Zhou, L.Q.; Xu, J.W.; Wang, J.Y.; Wei, Q.; Deng, Y.B.; Cui, X.W.; Dietrich, C.F. Artificial intelligence in breast ultrasound. World J. Radiol. 2019, 11, 19-26. [CrossRef]

124. Litjens, G.; Kooi, T.; Bejnordi, B.E.; Setio, A.A.A.; Ciompi, F.; Ghafoorian, M.; van der Laak, J.; van Ginneken, B.; Sanchez, C.I. A survey on deep learning in medical image analysis. Med. Image Anal. 2017, 42, 60-88. [CrossRef]

125. Muse, E.D.; Topol, E.J. Guiding ultrasound image capture with artificial intelligence. Lancet 2020, 396, 749. [CrossRef]

126. Drukker, L.; Noble, J.A.; Papageorghiou, A.T. Introduction to artificial intelligence in ultrasound imaging in obstetrics and gynecology. Ultrasound Obstet. Gynecol 2020, 56, 498-505. [CrossRef] [PubMed]

127. Lambin, P.; Rios-Velazquez, E.; Leijenaar, R.; Carvalho, S.; van Stiphout, R.G.; Granton, P.; Zegers, C.M.; Gillies, R.; Boellard, R.; Dekker, A.; et al. Radiomics: Extracting more information from medical images using advanced feature analysis. Eur. J. Cancer 2012, 48, 441-446. [CrossRef] [PubMed]

128. Rizzo, S.; Botta, F.; Raimondi, S.; Origgi, D.; Fanciullo, C.; Morganti, A.G.; Bellomi, M. Radiomics: The facts and the challenges of image analysis. Eur. Radiol. Exp. 2018, 2, 36. [CrossRef]

129. Theek, B.; Opacic, T.; Magnuska, Z.; Lammers, T.; Kiessling, F. Radiomic analysis of contrast-enhanced ultrasound data. Sci. Rep. 2018, 8, 11359. [CrossRef]

130. Parekh, V.S.; Jacobs, M.A. Deep learning and radiomics in precision medicine. Expert. Rev. Precis. Med. Drug Dev. 2019, 4, 59-72. [CrossRef] [PubMed]

131. Brattain, L.J.; Telfer, B.A.; Dhyani, M.; Grajo, J.R.; Samir, A.E. Machine learning for medical ultrasound: Status, methods, and future opportunities. Abdom Radiol. 2018, 43, 786-799. [CrossRef]

132. Soffer, S.; Ben-Cohen, A.; Shimon, O.; Amitai, M.M.; Greenspan, H.; Klang, E. Convolutional Neural Networks for Radiologic Images: A Radiologist's Guide. Radiology 2019, 290, 590-606. [CrossRef]

133. Han, A.; Byra, M.; Heba, E.; Andre, M.P.; Erdman, J.W., Jr.; Loomba, R.; Sirlin, C.B.; O’Brien, W.D., Jr. Noninvasive Diagnosis of Nonalcoholic Fatty Liver Disease and Quantification of Liver Fat with Radiofrequency Ultrasound Data Using One-dimensional Convolutional Neural Networks. Radiology 2020, 295, 342-350. [CrossRef]

134. Biswas, M.; Kuppili, V.; Edla, D.R.; Suri, H.S.; Saba, L.; Marinhoe, R.T.; Sanches, J.M.; Suri, J.S. Symtosis: A liver ultrasound tissue characterization and risk stratification in optimized deep learning paradigm. Comput. Methods Programs Biomed. 2018, 155, 165-177. [CrossRef]

135. Byra, M.; Styczynski, G.; Szmigielski, C.; Kalinowski, P.; Michalowski, L.; Paluszkiewicz, R.; Ziarkiewicz-Wroblewska, B.; Zieniewicz, K.; Sobieraj, P.; Nowicki, A. Transfer learning with deep convolutional neural network for liver steatosis assessment in ultrasound images. Int. J. Comput. Assist. Radiol. Surg. 2018, 13, 1895-1903. [CrossRef]

136. Cao, W.; An, X.; Cong, L.; Lyu, C.; Zhou, Q.; Guo, R. Application of Deep Learning in Quantitative Analysis of 2-Dimensional Ultrasound Imaging of Nonalcoholic Fatty Liver Disease. J. Ultrasound Med. 2020, 39, 51-59. [CrossRef] [PubMed] 
137. Bharti, P.; Mittal, D.; Ananthasivan, R. Preliminary Study of Chronic Liver Classification on Ultrasound Images Using an Ensemble Model. Ultrason. Imaging 2018, 40, 357-379. [CrossRef] [PubMed]

138. Hassan, T.M.; Elmogy, M.; Sallam, E.-S. Diagnosis of Focal Liver Diseases Based on Deep Learning Technique for Ultrasound Images. Arab. J. Sci. Eng. 2017, 42, 3127-3140. [CrossRef]

139. Sato, M.; Morimoto, K.; Kajihara, S.; Tateishi, R.; Shiina, S.; Koike, K.; Yatomi, Y. Machine-learning Approach for the Development of a Novel Predictive Model for the Diagnosis of Hepatocellular Carcinoma. Sci. Rep. 2019, 9, 7704. [CrossRef]

140. Schmauch, B.; Herent, P.; Jehanno, P.; Dehaene, O.; Saillard, C.; Aube, C.; Luciani, A.; Lassau, N.; Jegou, S. Diagnosis of focal liver lesions from ultrasound using deep learning. Diagn. Interv. Imaging 2019, 100, 227-233. [CrossRef]

141. Durot, I.; Akhbardeh, A.; Sagreiya, H.; Loening, A.M.; Rubin, D.L. A New Multimodel Machine Learning Framework to Improve Hepatic Fibrosis Grading Using Ultrasound Elastography Systems from Different Vendors. Ultrasound Med. Biol. 2020, 46, 26-33. [CrossRef]

142. Bruno, M.A.; Walker, E.A.; Abujudeh, H.H. Understanding and Confronting Our Mistakes: The Epidemiology of Error in Radiology and Strategies for Error Reduction. Radiographics 2015, 35, 1668-1676. [CrossRef] [PubMed]

143. Blumenthal-Barby, J.S.; Krieger, H. Cognitive biases and heuristics in medical decision making: A critical review using a systematic search strategy. Med. Decis. Mak. 2015, 35, 539-557. [CrossRef] [PubMed] 